Aus der Klinik für Hämatologie und Medizinische Onkologie (Prof. Dr. med. L. Trümper)

Der Medizinischen Fakultät der Universität Göttingen

\title{
Analyse von Mikrosatelliteninstabilität und hMSH2-Expression bei Patienten mit akuter myeloischer Leukämie
}

\author{
INAUGURAL-DISSERTATION \\ zur Erlangung des Doktorgrades \\ der Medizinischen Fakultät der
}

Georg-August-Universität zu Göttingen

\author{
vorgelegt von \\ Petra Kohaus \\ aus \\ Kassel \\ Göttingen 2016
}


Dekan:

Referent/in

Ko-Referent/in:

Drittreferent/in:

Tag der mündlichen Prüfung:
Prof. Dr. rer. nat. H. K. Kroemer

Prof. Dr. med. F. Alves 


\section{Inhaltsverzeichnis}

1 Einleitung

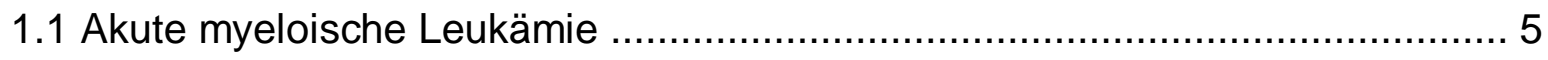

1.2 Genetische Instabilität........................................................................ 7

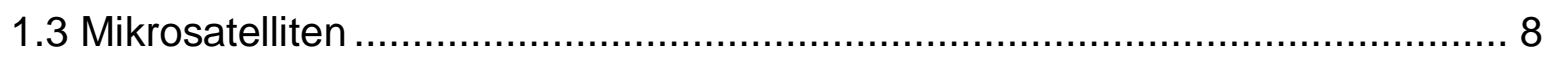

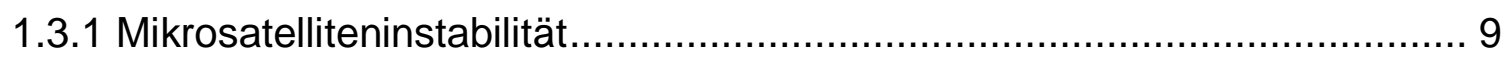

1.3.2 Loss of Heterozygosity (LOH) ....................................................... 10

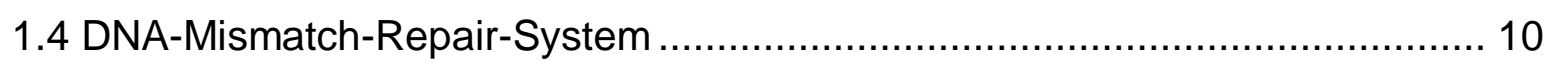

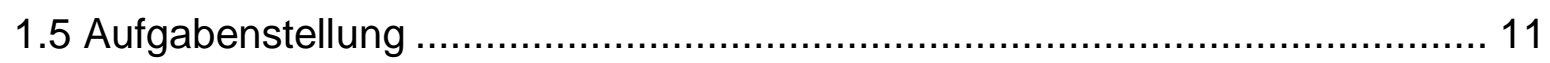

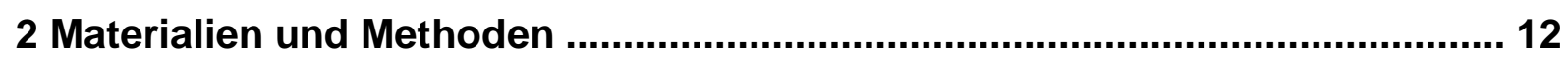

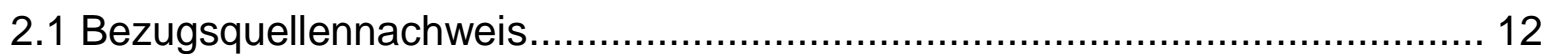

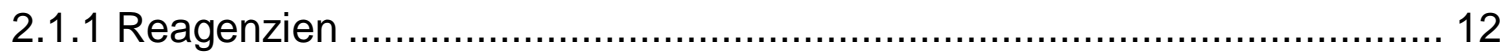

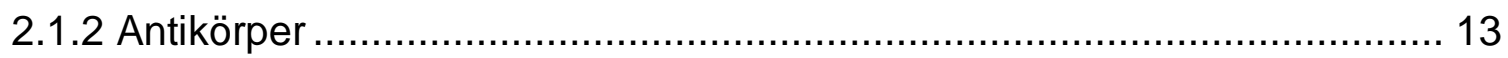

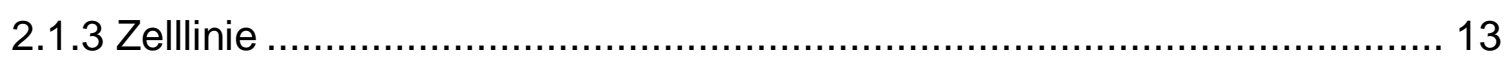

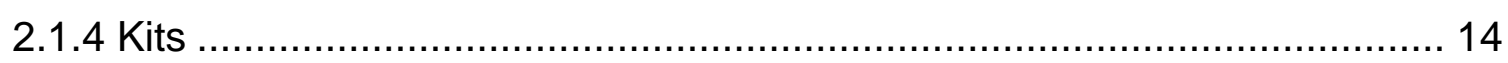

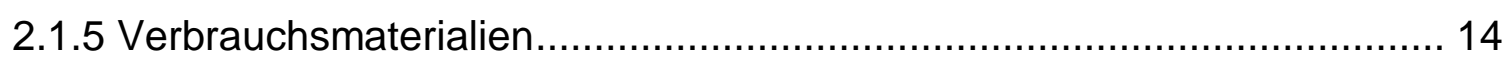

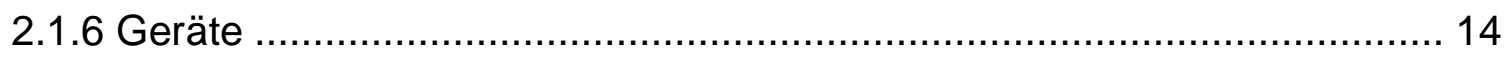

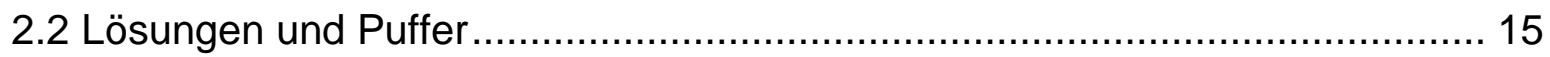

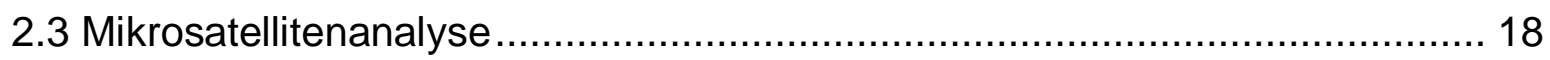

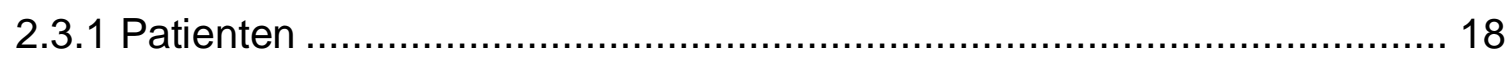

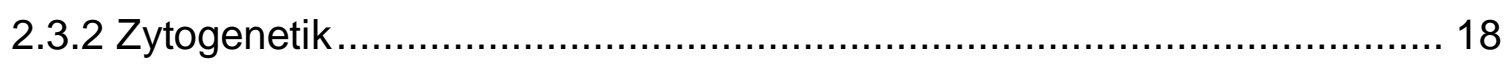

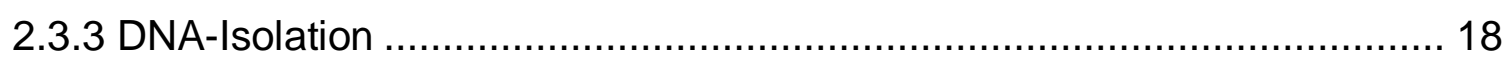

2.3.4 Konzentrationsbestimmung der isolierten DNA …............................... 19

2.3.5 Mikrosatellitenloci und Primer ......................................................... 19

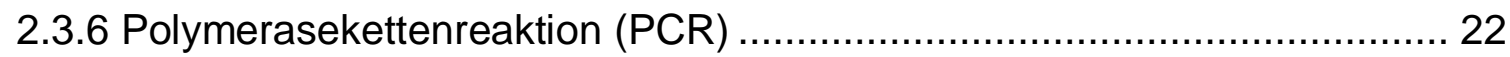

2.3.7 Polyacrylamidgel-Elektrophorese (PAGE) .......................................... 22

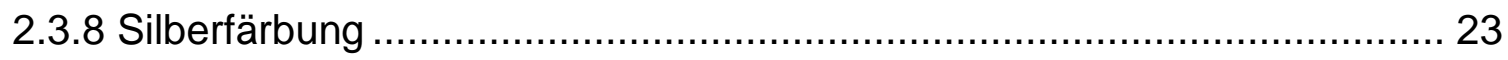

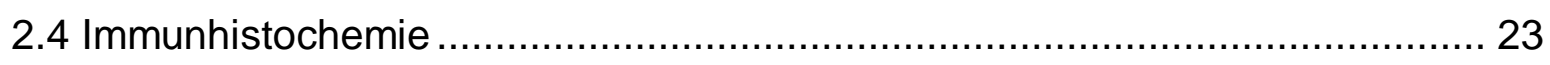

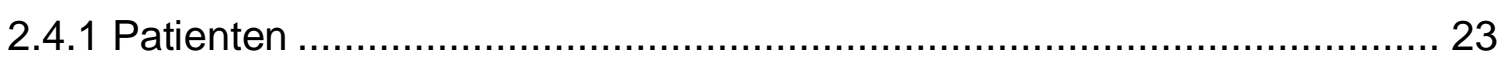

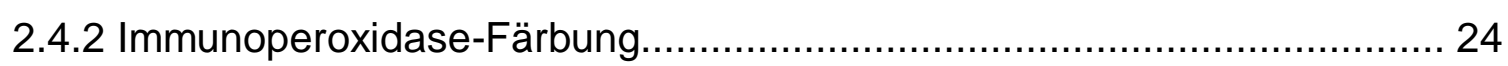

2.4.3 Hämalaun-Färbung und Konservierung ............................................. 24

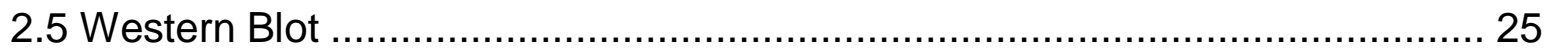




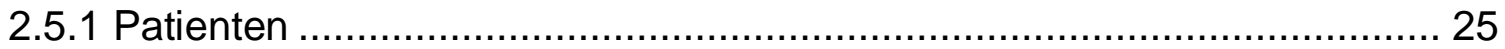

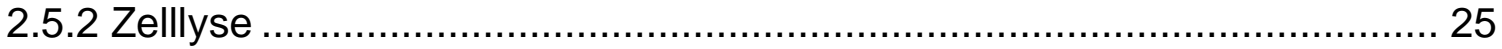

2.5.3 Proteinbestimmung nach Bradford ......................................................... 25

2.5.4 SDS-Polyacrylamidgel-Elektrophorese (SDS-PAGE) ........................... 25

2.5.5 Proteintransfer auf Nitrozellulosemembran ........................................ 26

2.5.6 Immundetektion und Enhanced-Chemoluminescence-Verfahren (ECL) .. 26

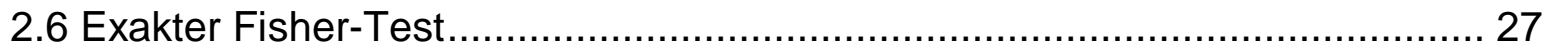

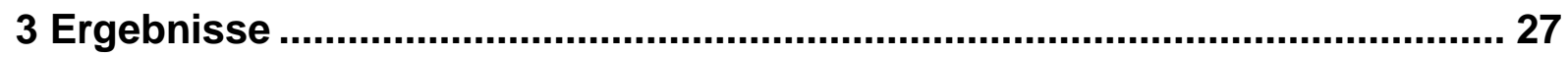

3.1 Detektion von LOH bei der Mikrosatellitenanalyse ................................... 27

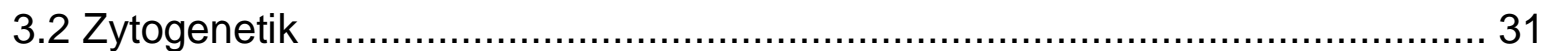

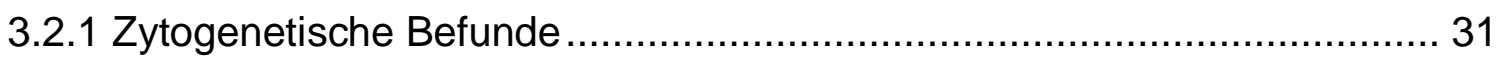

3.2.2 Zytogenetische Befunde in Korrelation zur Mikrosatellitenanalyse........... 31

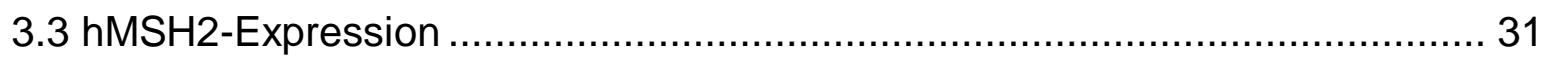

3.3.1 Immunhistochemischer Nachweis der hMSH2-Expression ...................... 31

3.3.2 Nachweis von hMSH2 in AML-Blasten mittels Western Blot ................... 34

3.3.3 hMSH2-Expression in Korrelation zur Mikrosatellitenanalyse.................. 36

3.3.4 Vergleich von hMSH2-Expression mit Ergebnissen der Zytogenetik........ 36

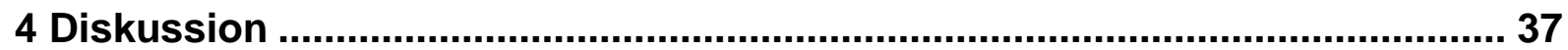

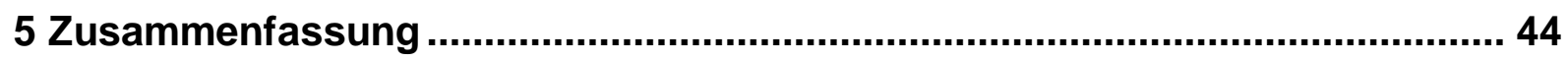

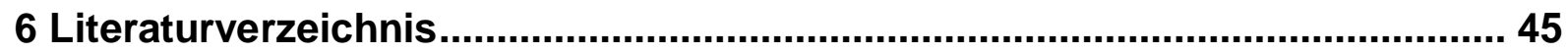

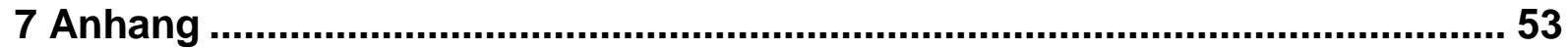

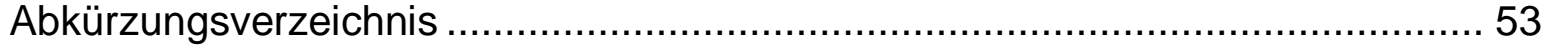

Abbildungs- und Tabellenverzeichnis......................................................... 56 


\section{Einleitung}

\subsection{Akute myeloische Leukämie}

Die akute myeloische Leukämie (AML) ist eine heterogene hämatologische Erkrankung, welche durch die Ausbreitung von Blasten im peripheren Blut, Knochenmark und anderen Geweben gekennzeichnet ist (O’Donnell et al. 2012). Diese maligne entarteten frühen Vorläuferzellen der normalen Blutbildung verlieren ihre Fähigkeit zur Ausreifung zu funktionsfähigen Blutzellen und entziehen sich den Kontrollmechanismen von Zellwachstum und Differenzierung. Als Folge der Ausbreitung der leukämischen Zellpopulation mit Verdrängung der normalen Blutbildung im Knochenmark kommt es zu einer Verminderung von Erythrozyten, funktionsfähigen Granulozyten und Thrombozyten, was zu Anämie, Infektionen und Blutungen führen kann (Kern et al. 2003).

Die AML ist zudem die häufigste maligne hämatologische Erkrankung bei Erwachsenen. Die weltweite Inzidenz der Erkrankung wird auf drei bis vier Neuerkrankungen pro 100.000 Menschen geschätzt. Trotz intensiver Forschung und neuer Therapien sowie prognostischer Marker ist die Prognose sehr variabel und mit einer hohen Letalität verbunden. Weniger als $50 \%$ der erwachsenen Patienten haben eine Gesamtüberlebenszeit von 5 Jahren, bei älteren Patienten beträgt die 2-Jahresüberlebensrate nur 20\% (Riva et al. 2012). Mit Ausnahme einiger weniger AML-Subtypen haben sich die Grundzüge der Therapie in den letzten 20 Jahren nicht signifikant verändert. Aus diesem Grund bleibt der Therapieerfolg für die Mehrheit der Patienten mit Langzeitüberlebensraten weiterhin schlecht (Gallipoli et al. 2015).

Zu den bekannten Risikofaktoren für die Entstehung einer AML gehören das Lebensalter, eine vorangegangene hämatologische Erkrankung und eine genetische Disposition ebenso wie eine Exposition gegenüber Viren, ionisierender Strahlung, Chemikalien wie z.B. Benzol sowie eine vorangegangene Behandlung mit Zytostatika. Die meisten Fälle von akuter myeloischer Leukämie entstehen de novo, ein kleinerer Teil tritt als sekundäre AML auf, d.h. nach myelodysplastischem Syndrom (MDS), nach einer myeloproliferativen Erkrankung oder therapieassoziert (Deschler und Lübbert 2006).

Die Einteilung der AML erfolgt nach zytomorphologischer und zytochemischer Beurteilung entsprechend der FAB-(French-American-British-) Klassifikation in verschiedene Subgruppen (Bennett et al. 1985). Diese wurde in der vorliegenden Arbeit verwendet, da die 
Patienten zum Zeitpunkt der Diagnosestellung nach dieser Einteilung klassifiziert wurden. Die neuere WHO-Klassifikation berücksichtigt zusätzlich zytogenetische und immunologische Kriterien zur Einteilung. Hierbei genügt bereits ein Blastenanteil von $20 \%$ zur Diagnose einer AML (Vardiman et al. 2009). Die Einteilung der AML entsprechend der FAB-Klassifikation ist in Tabelle 1 dargestellt.

Tab. 1: Einteilung der AML entsprechend der FAB-Klassifikation (entnommen aus: Kern et al. 2003. Die Verwendung erfolgt mit freundlicher Genehmigung des Zuckschwerdt Verlags München)

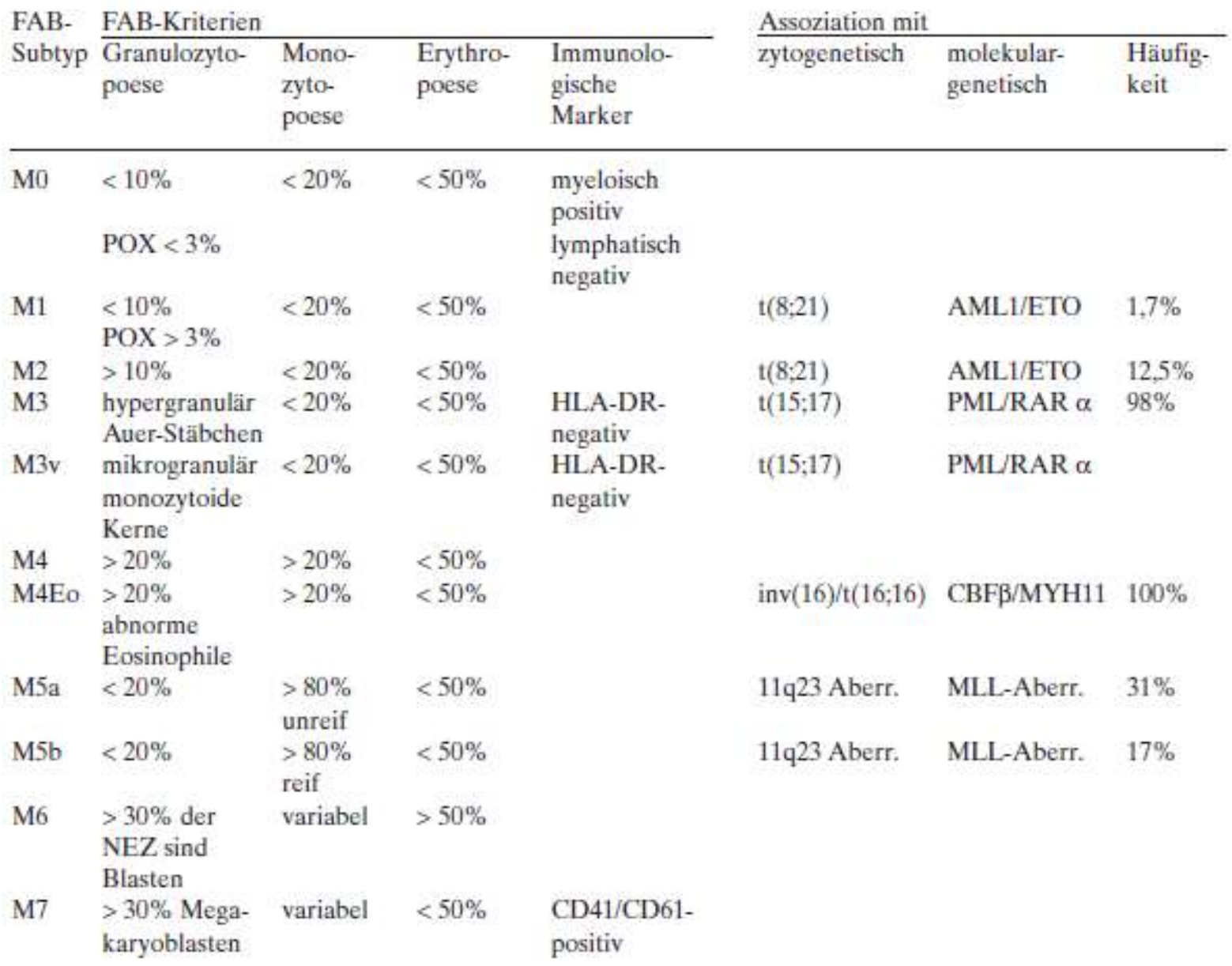

Die Therapie orientiert sich an aktuellen Studienprotokollen. Dabei kommen Anthracycline und Cytarabin zum Einsatz. Nach Induktionschemotherapie mit Erreichen einer Remission besteht die Möglichkeit zur Stammzelltransplantation (Döhner et al. 2010). Trotz wesentlicher Fortschritte bezüglich Chemotherapieschemata und supportiver Maßnahmen ist nur bei etwa 30-40\% der betroffenen Patienten eine dauerhafte Krankheitsfreiheit und endgültige Heilung zu erreichen. Neuere diagnostische Möglichkeiten der Zytogenetik, Molekulargenetik und funktionellen Zellanalytik erlauben jedoch tiefere Einblicke in Biologie und Pathogenese der akuten Leukämien, so dass Erfolgs- und Rückfallwahrscheinlichkeit in gewissem Umfang abschätzbar geworden sind und damit die Therapie risikoadaptiert ausgerichtet werden kann 
(Kern et al. 2003). Das Risikoprofil der AML in Abhängigkeit von Zytogenetik und molekularen Veränderungen ist in Tabelle 2 dargestellt.

Tab. 2: Einteilung der AML in Prognosegruppen nach Zytogenetik und molekularen Mutationen (entnommen aus: Herold et al. 2015. Die Verwendung erfolgt mit freundlicher Genehmigung von Dr. med. Gerd Herold)

\begin{tabular}{|c|c|}
\hline Prognosegruppe & Genetische Subgruppe \\
\hline $\begin{array}{l}\text { Günstige Prognosegruppe } \\
\text { (Niedrigrisiko) }\end{array}$ & $\begin{array}{l}\text { - } \mathrm{t}(15 ; 17) / \mathrm{PML}-\mathrm{RARA}(=\mathrm{APL}-\mathrm{RAR \alpha}) \\
\text { - } \mathrm{t}(18 ; 21) / \mathrm{AML}-\mathrm{ETO} \text { RUNX1-RUNX1T1 (Core-binding-factor- } \\
\text { [CBF] AML) } \\
\text { - inv(16)/t(16;16) CBFB-MYH11 } \\
\text { - Isolierte NPM1-Mutationen (normaler Karyotyp) } \\
\text { - Isolierte CEBPA-Mutationen (normaler Karyotyp) }\end{array}$ \\
\hline $\begin{array}{l}\text { Mittlere Prognosegruppe } \\
\text { (Intermediäres Risiko) }\end{array}$ & $\begin{array}{l}\text { - Normaler Karyotyp; NPM1-Mutation und FLT3-Längenmu- } \\
\text { tation (normaler Karyotyp); NPM1-Wildtyp ohne FTL3- } \\
\text { Längenmutation (normaler Karyotyp); NPM1-Wildtyp ohne } \\
\text { FTL3-Längenmutation (normaler Karyotyp) } \\
\text { - Trisomie 8; T(9;11)/MLLT3 MLL }\end{array}$ \\
\hline $\begin{array}{l}\text { Ungünstige Prognosegruppe } \\
\text { (Hochrisiko) }\end{array}$ & $\begin{array}{l}\text { - Komplexe Abberationen ( } \geq 3 \text { chrom. Anomalien) } \\
\text { - Monosomie 7; t(6;9)(p23;q34); DEK-NUP214; t(v11)(v;q23); } \\
\text { MLL-Rearrangement; del(5q); del(7) } \\
\text { - Anomalien an Chromosom } 3 \\
\text { - FTL3-Längenmutationen (FTL3-LM/FTL3-ITD) } \\
\text { - MLL-PTD }\end{array}$ \\
\hline
\end{tabular}

\subsection{Genetische Instabilität}

Nach bisherigem Kenntnisstand wird für die Entstehung von Tumoren eine genetische Instabilität als ursächlich angenommen (Lengauer et al. 1998). Diese Instabilität kann auf verschiedenen Ebenen in Erscheinung treten:

- Instabilitäten der Gen-Sequenz (Basendeletionen, -insertionen und -tausch sowie Mikrosatelliteninstabiltäten), welche der zytogenetischen Analyse nicht zugänglich sind

- Veränderungen der Chromosomenanzahl (Zugewinn oder Verlust ganzer Chromosomen)

- Chromosomale Translokationen (Zugewinn oder Verlust von Chromosomanteilen)

- Genamplifikation (multiple Kopien von 0,5 bis 10 DNA-Megabasen)

Neoplasien myeloischer Zellen sind klonale Erkrankungen hämatopoetischer Stamm- oder Vorläuferzellen. Sie entstehen aus genetischen oder epigenetischen Veränderungen, welche zu einer Störung von Schlüsselprozessen wie Regeneration, Proliferation und Zelldifferenzierung führen (Murati et al. 2012). 
Das Fortschreiten der Erkrankung resultiert aus einer Akkumulation von Mutationen in Genen, die Zellwachstum und -differenzierung kontrollieren (Sallmyr et al. 2008). Die genauen Mechanismen, die zu einer genetischen Instabilität führen, sind bislang jedoch noch unklar. Es mehren sich Hinweise, dass genetische Veränderungen myeloischer Neoplasien zu einer Anreicherung reaktiver Sauerstoffspezies (reactive oxygen species - ROS) führen, welche dann DNA-Schäden zur Folge haben. Beispielsweise führen Fusionsgene wie etwa BCR-ABL bei der chronisch myeloischen Leukämie, FLT3/ITD bei der AML und auch RASMutationen bei MDS zu einer ROS-Produktion. Weitere Theorien zur Entstehung von Leukämien weisen darauf hin, dass ein Teil der onkogenen Veränderungen der AML epigenetischer Natur ist (Figueroa et al. 2010).

In der vorliegenden Arbeit gilt das Hauptinteresse der Detektion genetischer Instabilitäten mittels Mikrosatellitenanalyse. Basierend auf der Theorie des mutator phenotype ist die hohe Anzahl von Mutationen in Tumorzellen nicht durch die geringe Mutationsrate zu erklären, die in normalen Zellen zu beobachten ist. Vielmehr manifestiert sich bereits früh in der Tumorgenese eine erhöhte Mutagenität, welche in Kombination mit klonaler Selektion zu einem Proliferationsvorteil der Tumorzellen führt. Die erhöhte Mutationsrate lässt sich so erklären, dass es initial zur Mutation von Genen kommt, die zur Aufrechterhaltung des mismatch repair-Systems erforderlich sind. Aufgrund der daraus resultierenden Ineffizienz dieses Systems können Fehler bei der DNA-Synthese nicht mehr erkannt bzw. repariert werden, was ein erhöhtes Auftreten von Mutationen zur Folge hat. Im Verlauf kommt es u. a. zur Aktivierung von Protoonkogenen bzw. Inaktivierung von Tumorsuppressor-Genen, was zur malignen Entartung führt (Loeb 1998).

Eine Möglichkeit zur Bestimmung der genetischen Instabilität bietet die Analyse von Mikrosatelliten, auf die im folgenden Kapitel näher eingegangen wird.

\subsection{Mikrosatelliten}

Bei Mikrosatelliten handelt es sich um repetitive, nicht kodierende, einfache DNA-Sequenzen von 1 bis 6 Basenpaaren, die sowohl im eukaryotischen wie auch im prokaryotischen Genom weit verbreitet sind. Aufgrund der besonderen Eigenschaft, höhere Mutationsraten als das übrige Genom zu tolerieren, werden sie allgemein als genetische Marker benutzt. In den letzten Jahren zogen Mikrosatelliten aus verschiedenen Gründen die Aufmerksamkeit von Forschern auf sich. Zu erwähnen ist beispielsweise die ausgedehnte Nutzung zur Genkartierung, der Zusammenhang zwischen der Instabilität der Anzahl der Sequenzwiederholungen und genetischen Erkrankungen beim Menschen, die praktikable 
und einfache Handhabung bei Untersuchungen der Populationsgenetik sowie für Genotypisierung und Vaterschaftsanalysen. Aufgrund der ausgeprägten Fähigkeit zur interindividuellen Differenzierung findet die Analyse von Mikrosatelliten auch in der Rechtsmedizin Anwendung (Oliveira et al. 2006).

\subsubsection{Mikrosatelliteninstabilität}

Um die hohe Mutationsrate in Mikrosatelliten zu erklären, wurden mehrere Mechanismen diskutiert, wie beispielsweise Fehler in der Rekombination, ungleiches Crossing-Over oder ein Gleiten der Polymerase während der Replikation oder Reparatur (Strand et al. 1993). So kann es während der DNA-Synthese gelegentlich vorkommen, dass sich die DNA-Stränge trennen und sich falsch wieder aneinander anlagern. Dies hat die Entstehung einer Heteroduplex-DNA zur Folge. Hierbei ist die Anzahl der Mikrosatellitenwiederholungen in Ursprungs-DNA und dem neu synthetisierten Strang unterschiedlich groß (Jiricny 2006). Befinden sich die ungepaarten Basen im Folgestrang, führt die weitere Synthese zu einer Verlängerung des Abschnitts, während ungepaarte Basen im Leitstrang zu einer Verkürzung führen (Strand et al. 1993). Die ungepaarten Nukleotide, die sich zum Teil extrahelical befinden, werden auch als insertion/deletion loops (IDLs) bezeichnet.

Bei Abwesenheit eines mismatch-repair-Systems bleiben die Basenfehlpaarungen und IDLs unkorrigiert, was zu einem mutator phenotype führt und mit einer Mikrosatelliteninstabilität (MSI) einhergeht (Jiricny 2006). Diese durch Zugewinn oder Verlust von kleinen repetitiven Einheiten innerhalb der Mikrosatellitensequenzen entstandenen IDLs kennzeichnen die Mikrosatelliteninstabilität (Peltomäki 2003).

MSI ist ein Kennzeichen für ein defizientes mismatch-repair-System, da Mikrosatelliten besonders anfällig für Replikationsfehler sind. MSI spielt auch eine wichtige Rolle in der Diagnostik sowohl von sporadisch auftretendem als auch genetisch bedingten kolorektalen Karzinomen. Beim HNPCC (hereditäres non-polypöses Kolonkarzinom) zeigt sich in mehr als $90 \%$ der Fälle eine MSI, im Gegensatz zu sporadisch auftretenden kolorektalen Karzinomen, bei denen dies nur bei $10-15 \%$ zutrifft. Aus diesem Grund wird die Mikrosatellitenanalyse gewöhnlich als erstes diagnostisches Screening für HNPCC verwendet (Müller et al. 2004). Die Inzidenzen von MSI für Tumoren des Magens und des Endometriums sind mit $18 \%$ bzw. 22\% vergleichsweise niedrig (Peltomäki et al. 1993). Die Mikrosatellitenanalyse eignet sich zur Identifikation von LOH (loss of heterozygosity) sowie zur Detektion einer Mikrosatelliteninstabilität als Ergebnis einer Defizienz des mismatchrepair-Systems. Auf die Bedeutung der $\mathrm{LOH}$ wird im folgenden Kapitel näher eingegangen. 


\subsubsection{Loss of Heterozygosity (LOH)}

Loss of heterozygosity ( $\mathrm{LOH}$ ) bezeichnet den Verlust eines Allels bei ursprünglich heterozygoter Ausprägung (Weinberg 1991). Ein Tumorsuppressor-Gen verliert seine Tumor unterdrückende Funktion, wenn beide Allele der homologen Chromosomen beeinträchtigt sind. Ist eines der Allele intakt, kann das normale Genprodukt hergestellt werden, welches fähig ist, die Zellproliferation zu unterdrücken. Aus diesem Grund erfordert die Tumorgenese in Form eines Tumorsuppressor-Gen-Verlustes die Fehlfunktion beider Gene, was zu einer vollständigen Schädigung beider Allele führt (Senda 2005). Ist eine Kopie eines Tumorsuppressor-Gens bereits durch eine Mutation inaktiviert, führt der Verlust des zweiten, nicht mutierten (wild-typ) Allels zur Homozygotie. Die Chromosomenregion kann dann durch ein Duplikat der entsprechenden Chromosomenregion, die das mutierte Allel trägt, ersetzt werden. Diese Schritte, die zu einer homozygoten Ausprägung eines mutierten Tumorsuppressor-Gens führen, beziehen die umliegenden Chromosomenregionen üblicherweise mit ein. Dementsprechend können DNA-Marker in der Nähe dieser Regionen ebenfalls einen Verlust der Heterozygotie aufweisen.

Es liegt nahe, dass die wiederholte Beobachtung von $\mathrm{LOH}$ eines bestimmten chromosomalen Markers in Zellen eines speziellen Tumors Hinweise auf das Vorhandensein eines in der Nähe lokalisierten Tumorsuppressor-Gens geben kann, dessen Verlust in der Pathogenese dieses Tumors von Bedeutung sein kann (Weinberg 1991).

\subsection{DNA-mismatch-repair-System}

Das DNA-mismatch-mepair-System (MMR) dient der Aufrechterhaltung der genetischen Stabilität. Dabei hat es zwei Kriterien zu erfüllen: Erstens muss es Fehler bei der Basenpaarung erkennen und zweitens den Reparaturmechanismus einleiten (Jiricny 2006). Das Modell eines MMR wurde bereits 1964 postuliert und später intensiv bei Bakterien, wie Escherichia coli (E. coli) erforscht (Modrich 1991). Bei E. coli wurden die Proteinkomplexe mutS, mutL, mutH und uvrD nachgewiesen, welche gemeinsam die o.g. Aufgaben erfüllen. Die Situation bei Eukaryoten ist komplizierter als bei E. coli. In menschlichen Zellen konnten fünf Homologe für mutS identifiziert werden, von denen die Homologe $\mathrm{MSH} 2, \mathrm{MSH} 3$ und MSH6 am MMR als Heterodimere teilnehmen. So leitet das von MSH2 und MSH6 gebildete Heterodimer MutSa die Reparatur von Nukleotid-mismatches und IDLs (insertion/deletion loops) von ein oder zwei extrahelicalen Nukleotiden ein. Die Reparatur von größeren IDLs wird vom Heterodimer MutS $\beta$ initiiert, welches sich aus MSH2 und MSH3 zusammensetzt (Jiricny 2006). Die zugehörigen Gene zählen zu den DNA-Stabilitätsgenen bzw. Caretaker- 
Genen. Sind diese inaktiviert, treten Mutationen in anderen Genen mit einer höheren Rate auf. Somit erhöht sich auch die Wahrscheinlichkeit einer Mutation in einem Onkogen oder Tumorsuppressor-Gen, wodurch die Tumorentstehung begünstigt wird (Vogelstein 2004).

Die Identifikation des Genortes von hMSH2, einem Homolog von mutS aus E. coli, gelang 1993 auf Chromosom 2 des Menschen (2p22-21). Aufgrund der Nähe zu einem am HNPCCSyndrom beteiligten Genort wurde eine Assoziation zu HNPCC vermutet (Fishel 1993). So zeigt sich eine Anfälligkeit für das HNPCC-Syndrom bei Keimbahnmutationen von Genen des DNA-mismatch-repair-Systems (MMR). Hierbei ist MSH2 zu etwa $40 \%$ betroffen (Peltomäki 2001).

\subsection{Aufgabenstellung}

Die Bedeutung von Mikrosatellitenalterationen in malignen Tumoren, als auch Leukämien ist trotz intensiver Forschungstätigkeit bisher nicht ausreichend geklärt.

In der vorliegenden Arbeit soll mithilfe von 18 ausgewählten Markern untersucht werden, ob bei der AML Mikrosatelliteninstabilität nachzuweisen ist. Dabei werden Mikrosatellitenanalysen an Knochenmarkaspiraten von AML-Patienten im Vergleich zu deren ReferenzDNA aus Bukkalepithel durchgeführt. Zusätzlich soll die Frage geklärt werden, ob das Auftreten von Mikrosatelliteninstabilität mit einer stärkeren Ausprägung chromosomaler Anomalien einhergeht, als möglicher Hinweis auf eine genetische Instabilität. Desweiteren soll untersucht werden, ob eine verminderte Expression von hMSH2 bei der AML mit einem verstärkten Auftreten von Mikrosatelliteninstabiltäten bzw. chromosomalen Abberationen einhergeht.

Zur Validierung der Hypothese einer erhöhten Prävalenz von Mikrosatelliteninstabilität und chromosomalen Abberationen als Zeichen eines defekten DNA-mismatch-repair-Systems sollen die Ergebnisse der Mikrosatellitenanalyse und der Zytogenetik mit dem Expressionsmuster des MMR-assoziierten hMSH2-Proteins in immunhistochemischen Untersuchungen von Knochenmarkausstrichen bzw. mittels Western Blot aus Knochenmarkaspiraten korreliert werden. 


\section{Materialien und Methoden}

\subsection{Bezugsquellennachweis}

Nachfolgend sind die verwendeten Reagenzien, Antikörper, Verbrauchsmaterialien und Geräte mit Herstellernachweis in alphabetischer Reihenfolge aufgeführt.

\subsubsection{Reagenzien}

- $\quad$ AccuGel ${ }^{\mathrm{TM}}$ 29:1 (40\% Acrylamide : Bisacrylamide)

- Aceton

- Ammoniumperoxodisulfat

- Aprotinin

- BenchMark $^{\mathrm{TM}}$ Protein Ladder

- Borsäure

- Bromphenolblau

- Coomassie Brilliant-Blue G250

- $\quad$ DAB (3,3'-Diaminobenzidin)

- DNA-Leiter (pUC19 DNA/Mspl (Hpall) Marker)

- Dimethylsulfoxid (DMSO)

- Dinukleotidtriphosphate (dNTP)

- Dithiothreiol (DTT)

- Ethylendiamintetraessigsäure (EDTA)

- Essigsäure

- Ethylenguanintetraessigsäure (EGTA)

- Ethanol absolut $(99,8 \%)$

- Formaldehyd 37\%

- Formamid

- Gelatine

- Glycin

- Harnstoff

- Isopropanol

- Leupeptin

- Mayers Hämalaunlösung

- Methanol

- Mineralöl

- Natriumcarbonat
National Diagnostics, Atlanta, USA

E. Merck, Darmstadt

E. Merck, Darmstadt

Sigma, Deisenhofen

GIBCO BRL, Gaithersburg, USA

E. Merck, Darmstadt

Sigma, Deisenhofen

Sigma, Deisenhofen

DAKO, Hamburg

MBI Fermentas, Vilnius, Litauen

Sigma, Deisenhofen

Boehringer, Mannheim

Sigma, Deisenhofen

Sigma, Deisenhofen

E. Merck, Darmstadt

Sigma, Deisenhofen

Baker, Deventer, Niederlande

E. Merck, Darmstadt

E. Merck, Darmstadt

E. Merck, Darmstadt

E. Merck, Darmstadt

E. Merck, Darmstadt

E. Merck, Darmstadt

Sigma, Deisenhofen

E. Merck, Darmstadt

E. Merck, Darmstadt

Sigma, Deisenhofen

E. Merck, Darmstadt 
- Natriumchlorid

- Natriumduodecylsulfat (SDS)

- Natriumfluorid

- Natriumhydroxid-Plätzchen

- Natrium-Orthovanadat

- Natronlauge (1 N und $5 \mathrm{~N}$ )

- $\quad$ Nonidet P-40 (NP-40)

- Phosphate Buffered Saline (PBS) Tabletten

- Pepstatin A

- Phosphorsäure

- Phenylmethylsulfonylfluorid (PMSF)

- Ponceau S

- Propanol

- Rothistol

- Silbernitrat

- $\quad$ SurfaSil ${ }^{\mathrm{TM}}$

- Taq DNA Polymerase

- $\quad$ N,N,N',N'-Tetramethylethylendiamin (TEMED)

- Trichloressigsäure (TCA)

- Tris(hydroxymethyl)aminomethan (Tris)

- Tris(hydroxymethyl)aminomethan- $\mathrm{HCl}$ (Tris $\mathrm{HCl}$ )

- Triton X-100

- Tween 20

- Vitro-Clud

\subsubsection{Antikörper}

- hMSH2 (Ab-2), muriner monoklonaler lg $\mathrm{G}_{1}$-Antikörper

- biotinylierter Sekundärantikörper (Ziege)
Paesel + Lorei, Hanau

Sigma, Deisenhofen

Sigma, Deisenhofen

E. Merck, Darmstadt

Sigma, Deisenhofen

E. Merck, Darmstadt

Fluka, Buchs, Schweiz

Sigma, Deisenhofen

Sigma, Deisenhofen

E. Merck, Darmstadt

Sigma, Deisenhofen

Sigma, Deisenhofen

Fluka, Neu-Ulm

E. Merck, Darmstadt

Paesel + Lorei, Frankfurt a. M.

Pierce, Rockford, USA

GIBCO BRL, Gaithersburg, USA

E. Merck, Darmstadt

E. Merck, Darmstadt

Paesel + Lorei, Frankfurt a. M.

Paesel + Lorei, Frankfurt a. M.

Serva Feinbiochemica, Hamburg

Serva Feinbiochemica, Hamburg

R. Langenbrinck, Emmendingen

\subsubsection{Zelllinie}

- KG-1 (humane AML-Zelllinie)

Dianova/Oncogene Research Products, Hamburg

Bio-Rad, Hercules, USA

Deutsche Sammlung von Mikroorganismen und Zellkulturen $\mathrm{GmbH}$, DSM ACC 14, Braunschweig 


\subsubsection{Kits}

- QIAamp Blood Kit

- DAKO Catalyzed Signal Amplification (CSA) System

- Enhanced-ChemoluminescenceReagenz (ECL)

\subsubsection{Verbrauchsmaterialien}

- Blottingpapier

- Deckgläser

- Einmal-Spritzen (2 ml)

- Halbmikroküvetten

- Nitrozellulosemembranen

- Objektträger „Superfrost Plus“

- PCR-Reaktionsgefäße $(0,5 \mathrm{ml})$

- Pipettenspitzen mit Filter $(10,20,100,1000 \mu l)$

- Reaktionsgefäße $(1,5,15,50 \mathrm{ml})$

- Reaktionsgefäße „Safe Lock“ (2 ml)

- Röntgenfilme „ECL-Hyperfilm“

\subsubsection{Geräte}

- Blotgerät „Trans-blot SD“

- Elektrophoresekammer (PAGE)

- Elektrophoresekammer (SDS-PAGE) „Mini-Protean II Cell“

- Elektrophorese-Netzgerät E734

- Feuchtkammer

- Gel-Digital-Video-Dokumentation "Concept No. 2“

- Magnetrührer „IKA Cembimag RCO“

- Mikroliterpipette

- Mikroskop „Axioskop 2“

- Mikrowellenherd „MWS 2819“
Qiagen $\mathrm{GmbH}$, Hilden

DAKO, Hamburg

Amersham, Arlington Heights, USA

Schleicher und Schüll, Göttingen

Carl Roth, Karlsruhe

B. Braun, Melsungen

Sarstedt, Sarstedt

Amersham, Arlington Heights, USA

Carl Roth, Karlsruhe

Biozym, Hess. Oldendorf

Biozym, Hess. Oldendorf

Sarstedt, Nümbrecht

Eppendorf-Netheler-Hinz, Hamburg

Amersham, Arlington Heights, USA

Bio-Rad, München

BioTech, St. Leon-Rot

Bio-Rad, München

Consort, Turnhout, Belgien

Krannich, Göttingen

INTAS, Göttingen

Janke \& Kunkel, Staufen i. Brsg.

Hamilton, Bonaduz, Schweiz

Zeiss, Göttingen

Bauknecht, Schorndorf 
- Thermocykler „TRIO Thermoblock ${ }^{\text {TM، }}$

pH-Meter „CG 710“

- Pipetten

(0,5-10 $\mu \mathrm{l}, 10-100 \mu \mathrm{l}, 100-1000 \mu \mathrm{l})$

- Spacer

- Spektralphotometer

- Waage

- Wasserbad „Medax“

- Wasserschüttelbad beheizt

- Vortexer „Vibrofix VF1 Electronic“

- Zentrifuge „Microfuge ${ }^{\mathrm{TM}} 11$ “
Biometra, Göttingen

Schott, Mainz

Eppendorf, Hamburg

Krannich, Göttingen

Schütt, Göttingen

Sartorius, Göttingen

Ernst + Schütt jr., Göttingen

Ges. für Labortechnik, Hannover

Janke \& Kunkel, Staufen i. Brsg.

Beckman Coulter, Fullerton, USA

\subsection{Lösungen und Puffer}

Die aufgeführten Lösungen wurden, sofern nicht anders angegeben, bei Raumtemperatur gelagert.

APS-Lösung (10\%)

$10 \mathrm{~g}$ Ammoniumperoxidisulfat ad $100 \mathrm{ml}$ Aqua bidest. Lagerung bei $4{ }^{\circ} \mathrm{C}$

\section{Bradford-Lösung}

50 mg Coomassie Brilliant-Blue G250, 50 ml Ethanol, 100 ml Phosphorsäure (85\%) ad 1 Aqua bidest. Filtration.

\section{DNA-Längenstandard}

$1 \mu$ l DNA-Leiter (pUC 19 DNA / Mspl (Hpall) Marker) ad $100 \mu$ I DNA-Laufpuffer. Lagerung bei $-20^{\circ} \mathrm{C}$.

\section{DNA-Laufpuffer}

9,5 ml Formamid, $10 \mathrm{mg}$ Bromphenolblau, $4 \mathrm{mg} \mathrm{NaOH}, 100 \mu \mathrm{l}$ 0,05 M EDTA ad $10 \mathrm{ml}$ Aqua bidest, Sättigung der Lösung mit Succrose. Lagerung bei $-20^{\circ} \mathrm{C}$.

\section{- Entwicklerlösung}

7,5 g NaOH, 2 ml Formaldehyd (37\%) ad 500 ml Aqua bidest. Ansetzen der Lösung unmittelbar vor Gebrauch. 
$108 \mathrm{~g}$ Tris, $55 \mathrm{~g}$ Borsäure, $4 \mathrm{ml}$ 0,05 M EDTA pH 8,0 ad 1 I Aqua bidest.

$10 \times$ Elektrophoresepuffer (Protein)

248 mM Tris, 1918 mM Glycin, 35 mM SDS

\section{Fixierlösung (Immunhistochemie)}

$17,5 \mathrm{ml}$ Aceton, $17,5 \mathrm{ml}$ Methanol, $15 \mathrm{ml}$ Formaldehyd (37\%). Lagerung bis zum Gebrauch auf Eis.

\section{Fixier- und Waschlösung}

$100 \mathrm{ml}$ Ethanol, $5 \mathrm{ml}$ Eisessig, ad 1 I Aqua bidest.

\section{dNTP-Lösung (2,5 mM)}

2,5 mM dATP, 2,5 mM dCTP, 2,5 mM dGTP, 2,5 mM dTTP. Lagerung bei -20 ${ }^{\circ} \mathrm{C}$.

\section{G-NETT}

0,25\% (w/v) Gelatine, 10\% (v/v) 10 x NETT-Puffer.

\section{4 x Lämmli-Puffer}

$10 \mathrm{mg}$ EDTA in 1,3 ml Aqua bidest (pH 8,45), 0,8 g DTT, 0,5 g Tris, 0,8 g SDS,

$10 \mathrm{~g}$ Glycerin, 1 Spatelspitze Bromphenolblau ad $20 \mathrm{ml}$ Aqua bidest.

\section{Natriumcarbonatlösung}

$7,5 \mathrm{~g} \mathrm{Na}_{2} \mathrm{CO}_{3}$ ad 1 I Aqua bidest.

\section{$10 \times$ NETT-Puffer}

1,5 M NaCl, 0,05 M EDTA (pH 8), 0,5 M Tris (pH 7,5), 0,5\% (v/v) Triton X-100.

\section{PCR-Ansatz $(20 \mu \mathrm{l})$}

7,2 $\mu \mathrm{l}$ Aqua bidest, 1,0 $\mu \mathrm{l} 10$ x PCR Buffer $(1 \mathrm{x})^{*}, 0,5 \mu \mathrm{lW}-1$ 1\% (0,05\%) *, 0,5 $\mu \mathrm{l}$ DMSO

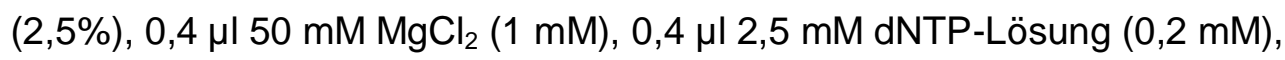

2,0 $\mu \mathrm{l}$ 7,5 $\mu \mathrm{M}$ Primer-Lösung $(0,75 \mu \mathrm{M}), 3,0 \mu \mathrm{l}$ Template-DNA (ca. 2,5 ng/ $\mu \mathrm{l}), 1$ Tropfen Mineralöl (Verdunstungsschutz), 5,0 $\mu \mathrm{l} 0,05 \mathrm{U} / \mu \mathrm{l}$ Taq DNA-Polymerase bei $94{ }^{\circ} \mathrm{C} z u$ Beginn des PCR-Programms.

Herstellung des PCR-Ansatzes auf Eis unmittelbar vor Gebrauch. Die Angaben in Klammern entsprechen den jeweiligen Endkonzentrationen.

* $=$ wurde zusammen mit der Taq DNA-Polymerase geliefert 


\section{Peroxidase-Blocklösung}

$10 \mathrm{ml} 1 \mathrm{M} \mathrm{H}_{2} \mathrm{O}_{2}$ ad $50 \mathrm{ml}$ Methanol, unmittelbar vor Gebrauch angesetzt.

\section{Polyacrylamidgel (10\%)}

$10 \mathrm{ml} \mathrm{AccuGel}{ }^{\mathrm{TM}}, 4 \mathrm{ml} 10 \times$ Elektrophoresepuffer (DNA), $19 \mathrm{~g}$ Harnstoff ad $40 \mathrm{ml}$ Aqua bidest. Lösen des Harnstoffs bei $50^{\circ} \mathrm{C}$ im Wasserbad.

\section{Ponceau S-Lösung}

2 g/l Ponceau S, 2\% (v/v) TCA. Lagerung lichtgeschützt.

\section{Primer-Lösung}

7,5 $\mu \mathrm{M}$ Primer (sense), 7,5 $\mu \mathrm{M}$ Primer (antisense). Lagerung bei $-20^{\circ} \mathrm{C}$.

\section{Mod. RIPA-Puffer}

$50 \mathrm{mM}$ Tris-HCl, $\mathrm{pH}$ 7,4, 1\% (v/v) NP-40, 0,25\% (w/v) Na-Deoxycholat, $150 \mathrm{mM} \mathrm{NaCl}$, $1 \mathrm{mM}$ EGTA, 1 mM PMSF, $1 \mu \mathrm{g} / \mathrm{ml}$ Aprotinin, $1 \mu \mathrm{g} / \mathrm{ml}$ Leupeptin, 1 $\mu \mathrm{g} / \mathrm{ml}$ Pepstatin A, $1 \mathrm{mM} \mathrm{NaF}, 1 \mathrm{mM} \mathrm{Na-Orthovanadat.}$

\section{Sammelgelpuffer}

1,5 M Tris- $\mathrm{HCl}, \mathrm{pH} 6,8,2 \%$ (w/v) SDS.

\section{Silbernitratlösung}

$0,5 \mathrm{~g} \mathrm{AgNO}_{3}$ ad $500 \mathrm{ml}$ Aqua bidest. Lagerung unter Lichtabschluß bei $4{ }^{\circ} \mathrm{C}$.

\section{Taq DNA-Polymerase $(0,05 \mathrm{U} / \mu \mathrm{l})$}

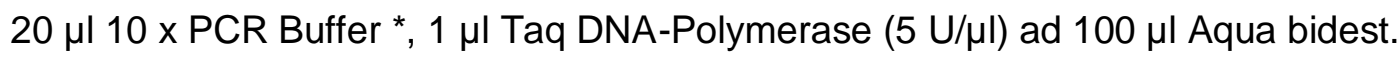

Ansetzen auf Eis unmittelbar vor Gebrauch.

* $=$ wurde mit der Taq DNA-Polymerase geliefert.

\section{TBS-Puffer}

$0,3 \mathrm{M} \mathrm{NaCl}, 0,05 \mathrm{M}$ Tris- $\mathrm{HCl}, 0,1 \%(\mathrm{v} / \mathrm{v})$ Tween 20. Einstellen des $\mathrm{pH}$-Wertes mit $\mathrm{NaOH}$ $(1 \mathrm{~N})$ auf 7,6 .

\section{Template-DNA (ca. $17 \mathrm{ng} / \mu \mathrm{l}$ )}

Einstellen mithilfe des Spektralphotometers. 


\section{- Transblot-Puffer}

$48 \mathrm{mM}$ Tris, 0,13 mM SDS, $39 \mathrm{mM}$ Glycin, 20\% (v/v) Methanol.

\section{Trenngelpuffer}

1,5 M Tris- $\mathrm{HCl}, \mathrm{pH} 8,8,2 \%(\mathrm{w} / \mathrm{v})$ SDS.

\subsection{Mikrosatellitenanalyse}

\subsubsection{Patienten}

Die Mikrosatellitenuntersuchungen wurden an insgesamt 40 Knochenmarkaspiraten durchgeführt, die Patienten mit $\mathrm{AML}$ im Rahmen der hämatologischen Diagnostik entnommen worden waren. Als Quelle für Referenz-DNA wurden bukkale Schleimhautzellen verwendet, die mithilfe eines sterilen Watteträgers von den jeweiligen Patienten gewonnen wurden. Die Aufbewahrung der Proben erfolgte bei $-20^{\circ} \mathrm{C}$. Ein hereditäres chromosomales Instabilitätssyndrom (Ataxia teleangiectatica, Fanconi-Anämie, Bloom-Syndrom, Xeroderma pigmentosum) wurde bei allen Patienten anamnestisch ausgeschlossen.

\subsubsection{Zytogenetik}

Die Chromosomenanalysen erfolgten durch Mitarbeiter des zytogenetischen Labors der Abteilung Hämatologie und Onkologie der Universität Göttingen. Es wurde dabei eine modifizierte GAG-Banden-Technik nach Kurzzeitkultur von Knochenmarkaspiraten verwendet (Stollmann et al. 1985). Die Chromosomentaxonomie erfolgte in Übereinstimmung mit dem International System for Human Cytogenetic Nomenclature (ISCN 1995, 1995).

\subsubsection{DNA-Isolation}

Zur Isolation der DNA aus Knochenmarkaspiraten und Bukkalschleimhautzellen wurde das QIAmp Blood Kit (Qiagen, Hilden) verwandt. Nach Entfernung von Proteinbeimengungen mittels Proteinase $\mathrm{K}$ wurde die DNA mit Ethanol ausgefällt und durch Zentrifugation auf einem feinporigen Siliziumfilter adsorbiert. Anschließend wurde die DNA mehrfach mit den enthaltenen Pufferlösungen gewaschen und zentrifugiert. Nach Eluierung erfolgte die Aufbewahrung der DNA bei $-20^{\circ} \mathrm{C}$. 


\subsubsection{Konzentrationsbestimmung der isolierten DNA}

Im Spektralfotometer wurden die Extinktionen der 1:100 verdünnten DNA-haltigen Filtrate bei den Wellenlängen 260 und 280 nm gemessen. Gemäß dem Lambert-Beerschen Gesetz ergaben sich die DNA-Konzentrationen durch Multiplikation der gemessenen Extinktionen mit einem Faktor, der über die Erstellung einer Standardeichkurve mittels verschiedener Nukleinsäure-Konzentrationen ermittelt wurde.

\subsubsection{Mikrosatellitenloci und Primer}

Es wurden 18 Mikrosatelliten auf 15 verschiedenen Chromosomenarmen untersucht, um einen repräsentativen Eindruck der Häufigkeit von LOH und MSI bei AML zu erhalten. Diese sind im Einzelnen:

- BAT-26, BAT-40 (Papadopoulos 1995, Samowitz et al.1999, Liu et al. 1996),

- CACNL1A3 (Gregg et al. 1993),

- D4S171 (Weber und May 1990),

- APC (Spirio et al. 1991, Senda et al. 2005),

- IRF1 (Maeck et al. 2000),

- D7S522 (Weissenbach et al. 1992, Zenklusen et al. 1994),

- WT1 (Haber et al. 1990, Coppes et al. 1993),

- D12S89 (Weissenbach et al. 1992, Stegmaier et al. 1995),

- RB1 (Yandell und Dryja 1989),

- NF1 (Lazaro et al. 1993),

- NM23-H1 (Hall et al. 1992, Tee et al. 2006),

- TP53 (Jones und Nakamura 1992),

- DCC (Fearon et al. 1990),

- PLCpr (Rothschild et al. 1992),

- D8S87 (Trapman et al. 1994, Weber et al. 1990),

- LPL (Bova et al. 1993) und

- D10S197 (Risio et al. 1996).

Die Marker wurden nach folgenden Kriterien ausgewählt:

- Enge chromosomale Beziehung zu einem Tumorsuppressor-Gen (D4S171, APC, IRF1, D7S522, D8S87, LPL, D10S197, WT1, D12S89, RB1, NF1, NM23-H1, TP53, DCC),

- hoher Heterogenitätsgrad (Ausnahme: BAT-26),

- Lokalisation auf häufig (1q, 5q, 7q, 12p, 13q, 17p, 18q, 20q) 
- bzw. selten (4q, 8p, 10p, 11p, 17q) in klonale Aberrationen involvierten Chromosomensegmenten bei MDS (HAASE et al. 1995).

Alle verwendeten Oligonukleotide wurden von der Firma NAPS (Göttingen) auf dem DNA/RNA-Synthesizer „Expedite 8009“ (Perceptive Biosystems, Wiesbaden) synthetisiert.

Die Primersequenzen und Loci der untersuchten Mikrosatelliten sind in Tabelle 3 aufgelistet. 


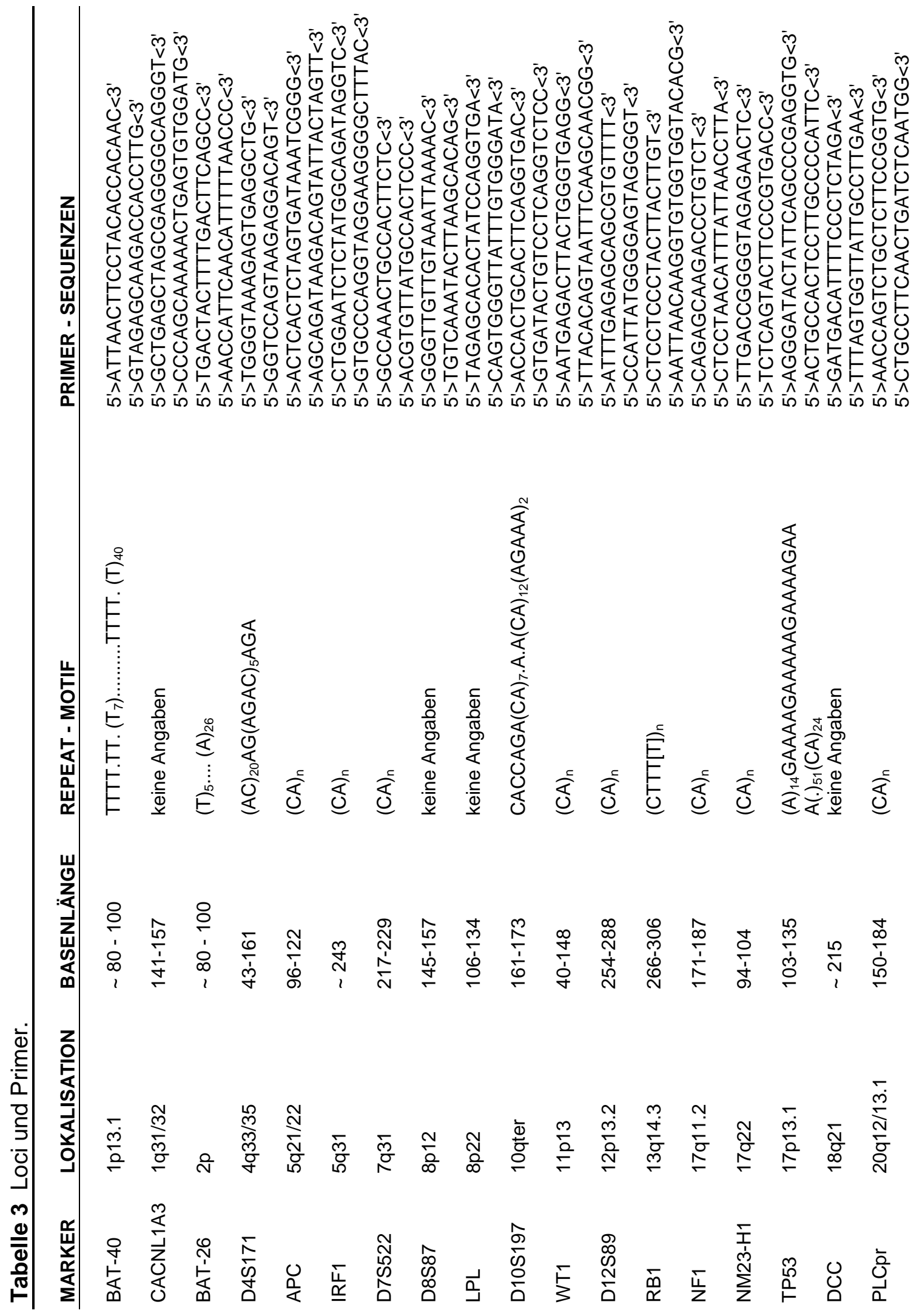




\subsubsection{Polymerasekettenreaktion (PCR)}

Die PCR ist eine Methode zur gezielten exponentiellen Amplifikation spezifischer DNAAbschnitte, die von zwei bekannten DNA-Sequenzen eingerahmt werden. In der vorliegenden Arbeit wurde sie nach einem modifizierten Originalprotokoll von Saiki et al. durchgeführt (1985). Hierbei werden zyklisch drei Reaktionsschritte durchlaufen, die sich in Dauer und Temperatur unterscheiden. Zunächst wird durch Erhitzung die DNA in ihre Einzelstränge aufgetrennt (Denaturierung). Anschließend erfolgt bei niedriger, primerspezifischer Temperatur eine Anlagerung der Primer an die DNA (Annealing). Im dritten Schritt wird durch die DNA-Polymerase der komplementäre Strang durch Anlagerung von Nukleotiden ausgehend vom Primer in Richtung 5 -Ende des Ursprungsstangs gebildet (Elongation). Im Verlauf der weiteren PCR-Zyklen steigt die Anzahl der Ziel-DNA exponentiell an, da sie selbst für die weitere Amplifikation als Matrize dient. Im Gegensatz dazu vermehren sich die langen PCR-Produkte nur linear, so dass die Ziel-DNA nach Reaktionsende in weitaus höherer Konzentration vorliegt.

Es wurden 36 PCR-Ansätze pro Patient durchgeführt (18 mit DNA aus Knochenmark und 18 mit DNA aus Bukkalschleimhautzellen). Als Negativkontrolle diente Aqua bidest anstelle von DNA. Die anschließende Lagerung der PCR-Produkte erfolgte bei $4{ }^{\circ} \mathrm{C}$. Nachfolgend sind Dauer und Temperaturen der einzelnen Reaktionsschritte aufgeführt (PCR-Programm):

- Denaturierung: 45 s (3 Min. während des ersten Zyklus) bei $94^{\circ} \mathrm{C}$

- Annealing: $30 \mathrm{~s}$

1. bei $53^{\circ} \mathrm{C}$ (BAT-40, D7S522, NF1, DCC) bzw.

2. bei $62{ }^{\circ} \mathrm{C}$ (BAT-26, D4S171, APC, IRF1, D8S87, LPL, D10S197, WT1, D12S89, NM23-H1, TP53, PLCpr) bzW.

3. bei $69^{\circ} \mathrm{C}(\mathrm{CACNL} 1 \mathrm{~A} 3)$

- Elongation: $25 \mathrm{~s}$ (10 Min. während des letzten Zyklus) bei $72{ }^{\circ} \mathrm{C}$

- Anzahl der Zyklen: 31

\subsubsection{Polyacrylamidgel-Elektrophorese (PAGE)}

Die PAGE dient zur Auftrennung von Nukleinsäuren nach ihrer Basenlänge. Unter Zugabe von Harnstoff ist durch Ausschaltung der Sekundärstruktur bei ausreichenden PolyacrylamidKonzentrationen eine sehr genaue Trennung möglich, weshalb dieses Verfahren zum Erkennen von MSI besonders gut geeignet ist.

In der vorliegenden Arbeit wurden 10-\%ige Polyacrylamidgele der Maße $20 \mathrm{~cm} \times 20 \mathrm{~cm}$ x 0,1 $\mathrm{cm}$ verwendet, deren Polymerisation nach Zugabe von $500 \mu \mathrm{l}$ APS-Lösung und $50 \mu \mathrm{l}$ 
TEMED eingeleitet wurde. Das Gel wurde zügig blasenfrei gegossen und zur Aussparung von 24 Probentaschen ein entsprechender Kamm eingesetzt. Nach 60-minütiger Polymerisation bei horizontaler Lagerung wurde das $\mathrm{Gel}$ in die mit einfach konzentriertem Elektrophoresepuffer gefüllte Elektrophoresekammer gestellt und der Taschenkamm vorsichtig entfernt.

Es wurde jeweils $4 \mu \mathrm{l}$ der zu analysierenden PCR-Produkte mit je $1 \mu \mathrm{l}$ DNA-Laufpuffer versetzt, anschließend kurz zentrifugiert, 5 Minuten im Thermocykler auf $95{ }^{\circ} \mathrm{C}$ erhitzt und auf Eis gelagert. Die Geltaschen wurden unter Verwendung einer Einmal-Spritze $(2 \mathrm{ml})$ zur Entfernung von Polyacrylamidresten mit Elektrophoresepuffer ausgespritzt. Anschließend erfolgte die Auftragung der PCR-Proben in die Taschen, so dass die jeweils einem Patienten zugehörigen DNA-Proben aus Knochenmarks- und Bukkal-DNA unter Verwendung desselben Primers nebeneinander aufgetrennt wurden. Zur Längenidentifizierung wurden in die erste Tasche $5 \mu$ l eines DNA-Längenstandards gegeben. Die letzte Tasche wurde mit der Negativkontrolle befüllt. Die Elektrophorese wurde bei $100 \mathrm{~V}$ über 12 Stunden durchgeführt.

\subsubsection{Silberfärbung}

In der vorliegenden Arbeit wurde eine leicht modifizierte Methode nach Budowle et al. (1991) angewendet. Das Gel wurde nach Beendigung der Elektrophorese im Wasserschüttelbad zweimal 3 Minuten in Fixier- und Waschlösung bewegt. Anschließend wurde das Gel für 10 Minuten in der zugegebenen Silbernitratlösung belassen. Zur Entfernung von überschüssiger Silbernitratlösung wurde das Gel in zwei 10-sekündigen Schritten mit Aqua bidest. gewaschen und anschließend für 20 - 30 Minuten in die Entwicklerlösung getaucht. Zur Fixierung der Färbeergebnisse erfolgte eine 5-minütige Inkubation in Natriumcarbonatlösung.

Die Untersuchung auf das Vorliegen von LOH und MSI erfolgte durch den Vergleich der Banden aus Knochenmarks- und Bukkal-DNA. Zur Dokumentation wurde das Gel-DigitalVideo-Dokumentationssystem verwandt mit anschließender Abspeicherung auf 3,5"Disketten.

\subsection{Immunhistochemie}

\subsubsection{Patienten}

Bei 15 Patienten wurden immunhistochemische Untersuchungen zur Beurteilung des Expressionsgrades des hMSH2-Proteins in den hämatopoetischen Zellen durchgeführt 
(Maeck et al. 2000). Diese erfolgten an Bröckelausstrichen von Knochenmarkaspiraten, die Patienten mit AML im Rahmen der hämato-onkologischen Diagnostik entnommen worden waren und bis zur Verwendung bei $-20^{\circ} \mathrm{C}$ aufbewahrt wurden.

\subsubsection{Immunoperoxidase-Färbung}

Durch 15-sekündige Inkubation in eisgekühlter Fixierlösung erfolgte die Fixierung und Zellmembranlyse der Bröckelausstrich-Präparate von Knochenmarkaspiraten. Anschließend wurde die in Teilen der hämatopoetischen Zellen enthaltene endogene Peroxidase geblockt, um falsch-positive Ergebnisse zu unterbinden, da zur Antikörperdetektion ein Immunoperoxidase-Verfahren verwendet werden sollte. Die Präparate wurden 10 Minuten lang in Peroxidase-Blocklösung bei $4{ }^{\circ} \mathrm{C}$ inkubiert. Anhand der fehlenden zytoplasmatischen Anfärbung reifer, normalerweise stark peroxidasehaltiger Granulozyten konnte der Erfolg des Verfahrens kontrolliert werden.

Das hMSH2-Protein wurde unter Verwendung des Catalyzed Signal Amplification (CSA) System (DAKO, Hamburg) nach Angaben des Herstellers detektiert. Die Nachweisreaktion basiert auf einer Amplifikationsreaktion durch peroxidasekatalysierte Ausfällung von Biotin. Zunächst wird dabei der gebundene hMSH2-Primärantikörper (Maus) von einem biotinylierten Sekundärantikörper (Ziege) detektiert, an den wiederum ein Streptavidin-BiotinPeroxidasekomplex bindet. An der Antigenbindungsstelle wird in Gegenwart von Wasserstoffperoxid die Bindung einer biotinylierten Phenolgruppe (Tyramid) katalysiert, was zu einer starken Zunahme der zur Verfügung stehenden Biotinmoleküle führt. Diese vermitteln im folgenden Schritt die Bindung von Streptavidin-Peroxidase-Konjugaten, welche bei Zugabe von 3,3'-Diaminobenzidin (DAB) und Wasserstoffperoxid zur Bildung eines braunen Präzipitates als eigentliche Nachweisreaktion führen.

\subsubsection{Hämalaun-Färbung und Konservierung}

Anschließend wurden die Präparate 10 Sekunden lang in ein Hämalaunbad (Mayers Hämalaunlösung) getaucht und dann unter fließendem Wasser gespült, bis kein Farbstoff mehr in Lösung ging. Die Entwässerung der Ausstriche erfolgte anschließend durch jeweils 30 -sekündiges Inkubieren in Ethanol (60\%), Ethanol (75\%), Ethanol (90\%), Isopropanol und Rothistol. Nach vollständiger Verdunstung des Rothistols wurden die Präparate unter Verwendung jeweils eines Tropfens Vitro-Clud eingedeckelt. Die Auswertung erfolgte lichtmikroskopisch. 


\subsection{Western Blot}

\subsubsection{Patienten}

Bei 12 Patienten wurde ergänzend die Expression des hMSH2-Proteins mittels Western Blot untersucht. Dies erfolgte an Blasten von Knochenmarkaspiraten, die Patienten mit AML im Rahmen der hämato-onkologischen Diagnostik entnommen worden waren und bis zur Verwendung bei $-20^{\circ}$ aufbewahrt wurden.

\subsubsection{Zelllyse}

Es wurden Blasten aus Knochenmarkaspiraten von AML-Patienten in Suspension sowie Zellen aus Kulturen (KG1) entnommen und bei 2000 Upm über 5 Minuten zentrifugiert. Der Überstand wurde abgesaugt und die Zellpellets wurden in $4{ }^{\circ} \mathrm{C}$ kaltes PBS überführt und erneut bei 2000 Upm über 5 Minuten zentrifugiert. Der Überstand wurde abgenommen und das Pellet in $1 \mathrm{ml}$ mod. RIPA-Puffer $/ 1 \times 10^{7}$ Zellen resuspendiert. Es folgte eine 20-minütige Inkubationszeit bei $4{ }^{\circ} \mathrm{C}$ auf einem Drehrad, danach wurde erneut zentrifugiert (15000 Upm über 20 Minuten bei $4^{\circ} \mathrm{C}$ ), um nicht lysierte Zellbestandteile zu entfernen. Das Lysat wurde zur Proteinbestimmung eingesetzt.

\subsubsection{Proteinbestimmung nach Bradford}

Entsprechend dem Originalprotokoll von Bradford (1976) wurden die Proteinkonzentrationen bestimmt. Jeweils $50 \mu \mathrm{l}$ einer mit Aqua bidest. hergestellten 1:10-Verdünnung der Lysate wurden mit $1 \mathrm{ml}$ Bradford-Lösung versetzt und über 20 Minuten in Halbmikroküvetten inkubiert. Die Extinktionen wurden anschließend bei $578 \mathrm{~nm}$ photometrisch gemessen. Die gefundenen Werte wurden zur Errechnung der Proteingehalte mit dem Faktor 4,2 multipliziert, entsprechend der über eine mit verschiedenen BSA-Konzentrationen ermittelten Standardeichkurve.

\subsubsection{SDS-Polyacrylamidgel-Elektrophorese (SDS-PAGE)}

Die SDS-PAGE ist ein elektrophoretisches Verfahren zur Auftrennung von Proteinen nach dem Molekulargewicht. Hierbei werden durch die Reagenzien SDS und DTT sowohl Sekundär- als auch Tertiärstrukturen ausgeschaltet. Zum Einsatz kamen in der vorliegenden Arbeit $0,075 \mathrm{~cm}$ durchmessende Gele mit einer Trenngellaufstärke von $6 \mathrm{~cm}$. Das 7,5-\%ige Trenngel setzte sich aus $10 \mathrm{ml}$ Aqua bidest, $5 \mathrm{ml}$ Trenngelpuffer und $5 \mathrm{ml} \mathrm{AccuGel}{ }^{\mathrm{TM}}$ zusammen. Nach Zugabe von $150 \mu$ l APS-Lösung und $40 \mu \mathrm{l}$ TEMED wurde das Gel 
gegossen und mit Aqua bidest überschichtet. Dieses wurde nach Erstarren des Gels mit Filterpapier wieder abgenommen. Das 3,7-\%ige Sammelgel bestand aus 4,7 ml Aqua bidest, $1,75 \mathrm{ml}$ Sammelgelpuffer sowie $0,9 \mathrm{ml} \mathrm{AccuGel}^{\mathrm{TM}}$ und wurde nach Zugabe von $80 \mu \mathrm{l}$ APSLösung und $20 \mu$ I TEMED auf das Trenngel gegossen. Vor Erstarren des Sammelgels wurde ein 12-Taschenkamm bis kurz oberhalb der Trenn-/Sammelgel-Grenze eingesetzt. Nach 4:1Verdünnung mit $4 \times$ Lämmli-Puffer und anschließendem 5-minütigem Erhitzen bei einer Temperatur von $95{ }^{\circ} \mathrm{C}$ wurden die zu analysierenden Proben (Proteingehalt von jeweils 35 $\mu \mathrm{g})$ in die Geltaschen des auspolymerisierten Gels pipettiert. Zusätzlich zu den Zelllysaten wurde ein Molekulargewichtsmarker (Benchmark Protein Ladder) mit dem Bereich von 10 bis 220 kD aufgetragen. Die Elektrophorese wurde bei $90 \mathrm{~V}$ über 2,5 Stunden durchgeführt.

\subsubsection{Proteintransfer auf Nitrozellulosemembran}

Das Gel wurde auf einer Nitrocellulosemembran zwischen zwei Lagen von jeweils einem dicken und drei dünnen in Transferpuffer getränkten und auf die Größe des Trenngels verkleinerten Blottingpapieren plaziert. Die untere Papierschicht kam auf die Anode, die obere auf die Kathode des Blotgerätes. Der Proteintransfer vom Gel auf die Membran erfolgte bei unbegrenzter Spannung und $1,4 \mathrm{~mA} / \mathrm{cm}^{2}$ für die Dauer von 1,5 Stunden. Die Membran wurde anschließend zur reversiblen Anfärbung der Proteine 1 Minute lang in Ponceau S inkubiert. Die Molekulargewichtsmarker wurden mit einem Stift gekennzeichnet. Anschließend wurde die Ponceau S-Lösung durch dreimaliges jeweils 20-minütiges Waschen in G-NETT entfernt.

\subsubsection{Immundetektion und Enhanced-Chemoluminescence- Verfahren (ECL)}

Alle Inkubationsschritte erfolgten auf einem Kippschüttler. Die Nitrocellulosemembran wurde 1 Stunde lang in G-NETT geschwenkt zur Absättigung unspezifischer Bindungsstellen. Anschließend wurde der hMSH2-Antikörper im Verhältnis 1:1000 mit G-NETT verdünnt und zusammen mit der Membran bei $4^{\circ} \mathrm{C}$ über Nacht inkubiert. Nach fünfmaligem Waschen in G-NETT für insgesamt 30 Minuten wurde als Sekundärantikörper ein MeerrettichPeroxidase-markierter Ziege-anti-Maus-Antikörper im Verhältnis 1:20000 in G-NETT für 1 Stunde bei Raumtemperatur auf die Membran gegeben. Anschließend erfolgte eine erneute fünfmalige Waschung mit G-NETT für 30 Minuten. Unter Zuhilfenahme eines ECL-Kits, dessen Hauptkomponenten Luminol und Wasserstoffperoxid waren, wurde die Antikörperdetektion durchgeführt. Hierbei führte eine peroxidaseinitiierte Reaktionskette zu einer Lumineszenz, die zur Belichtung des Films genutzt werden konnte. Beide ECL- 
Komponenten wurden in einer Dunkelkammer zu gleichen Teilen gemischt, zusammen mit der Membran für 1 Minute inkubiert und dann auf einen Röntgenfilm gelegt. Die Filmentwicklung wurde in einem Automaten durchgeführt.

\subsection{Exakter Fisher-Test}

Zur Auswertung der Ergebnisse und Prüfung eines statistischen Zusammenhangs zwischen dem Auftreten von LOH, MSI, Chromosomenaberrationen und der hMSH2-Expression wurde der exakte Fisher-Test für kleine Stichproben verwandt.

\section{Ergebnisse}

\subsection{Detektion von LOH bei der Mikrosatellitenanalyse}

Es wurden insgesamt 40 Patienten mit AML untersucht, darunter 18 Frauen und 22 Männer mit einem Durchschnittsalter von 59 Jahren zum Zeitpunkt der Probenentnahme (Spannweite: 17 - 79 Jahre). Entsprechend der FAB-Klassifikation konnten die Patienten den Subtypen wie folgt zugeordnet werden: Drei Patienten mit AML M0, 11 Patienten mit AML M1, fünf mit M2, vier mit M3, 11 mit M4, drei mit M5, kein Patient mit M6 und drei Patienten mit AML M7. In Tabelle 4 sind die untersuchten Patienten aufgelistet. Die Analyse der Mikrosatelliten konzentrierte sich auf 18 Loci, die jeweils vergleichend in der DNA von Blasten sowie in der von abgeschilfertem bukkalem Schleimhautepithel desselben Patienten untersucht wurden. So ergaben sich 720 untersuchte Mikrosatellitenpaare, von denen 663 (= 92\%) verwertbare Ergebnisse erbrachten. Typische Befunde der LOH sind exemplarisch in Abbildung 1 dargestellt.

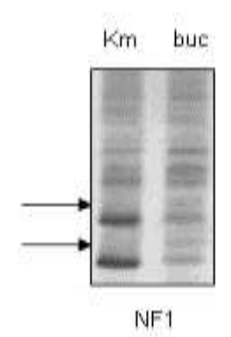

$[17 q 11.2]$

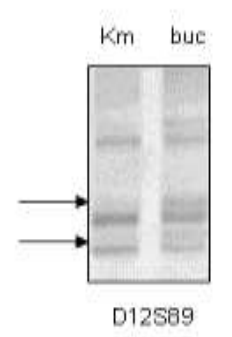

[12p13.2]
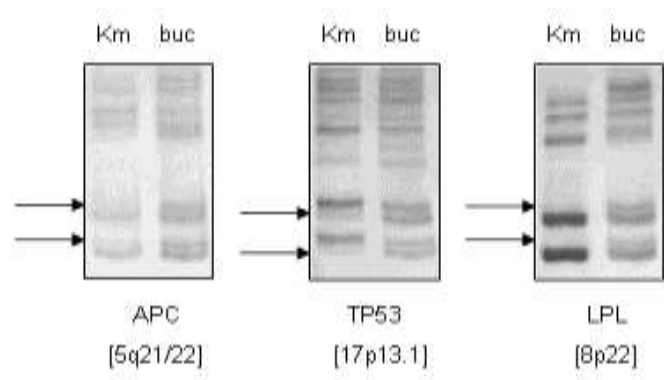

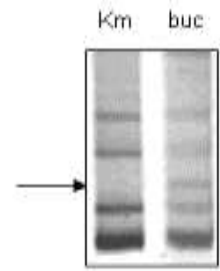

RB1

[13q14.3]

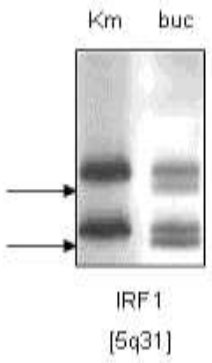

Abbildung 1: LOH an sieben verschiedenen Loci. Die untersuchten Mikrosatelliten und ihre chromosomale Lokalisation sind unter den jeweiligen Bandenpaaren angegeben. Allelverlust der Knochenmark-DNA wird durch Pfeile demonstriert. Abkürzungen: $\mathrm{Km}=$ Knochenmark-DNA; buc $=$ korrespondierende DNA aus Bukkalepithelzellen 
Insgesamt konnten bei zehn Patienten LOH nachgewiesen werden (25\%), bei zwei dieser Patienten sogar zweifach. Jedoch zeigte keiner der Patienten MSI. Die Verteilung der LOH auf die Subtypen ist in Tabelle 5 dargestellt. Der Marker NF1 (17q11.2) war bei fünf Patienten und somit am weitaus häufigsten betroffen. Bei einem Patienten mit AML M1, bei einem mit sekundärer AML M1 aus MDS, einem anderen mit M2, wieder einem anderen mit sekundärer AML M4 aus MDS und beim fünften Patienten mit einer therapieinduzierten AML M5 wurde bei NF1 ein LOH nachgewiesen.

Die beiden Patienten, die jeweils zwei LOH zeigten, hatten je einen davon beim Marker APC (5q21/22), wie in Tabelle 4 aufgeführt. Zusätzlich betroffen waren TP53 (17p13.1) und LPL (8p22), wie Abbildung 1 zeigt. Weiterhin konnten Allelverluste für Marker D12S89 (12p13.2) bei einem Patienten mit einer sekundären AML M1 aus MDS, für Marker RB1 (13q14.3) bei einem Patienten mit AML M2 sowie für Marker IRF1 (5q31) bei einem Patienten mit AML M4 nachgewiesen werden. In der vorliegenden Untersuchung wurden weder beim Subtyp M3 noch beim Subtyp M7 Allelverluste detektiert.

Auffällig war ein Anteil von über 44\% (4 von 9 Patienten) von positiven Befunden beim Auftreten von $\mathrm{LOH}$ bei Patienten mit sekundärer bzw. therapieassozierter AML im Vergleich zu 19,4\% (6 von 31) bei Patienten mit de-novo-AML. Diese Ergebnisse sind in Tabelle 4 zusammengefasst. 


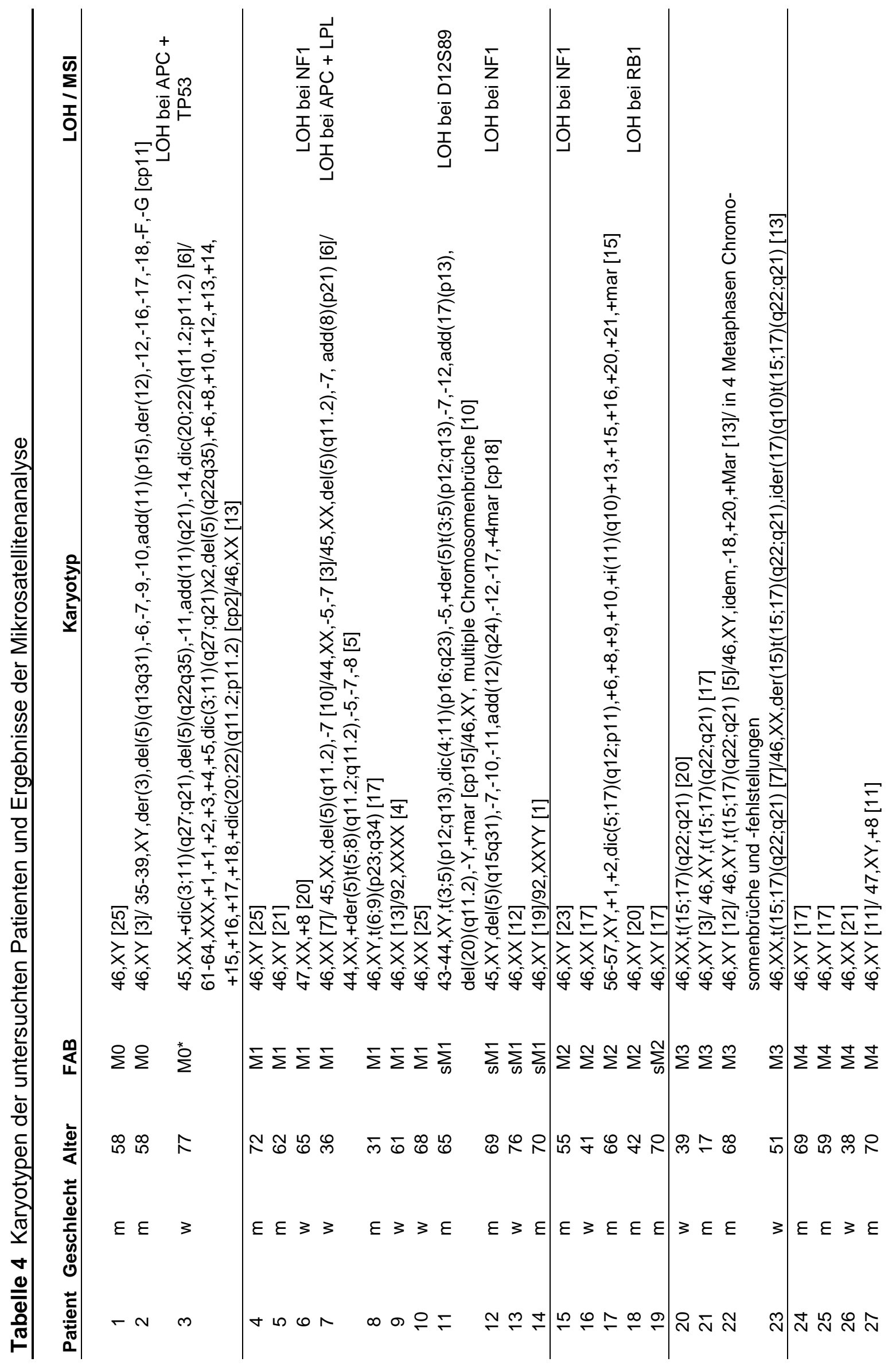




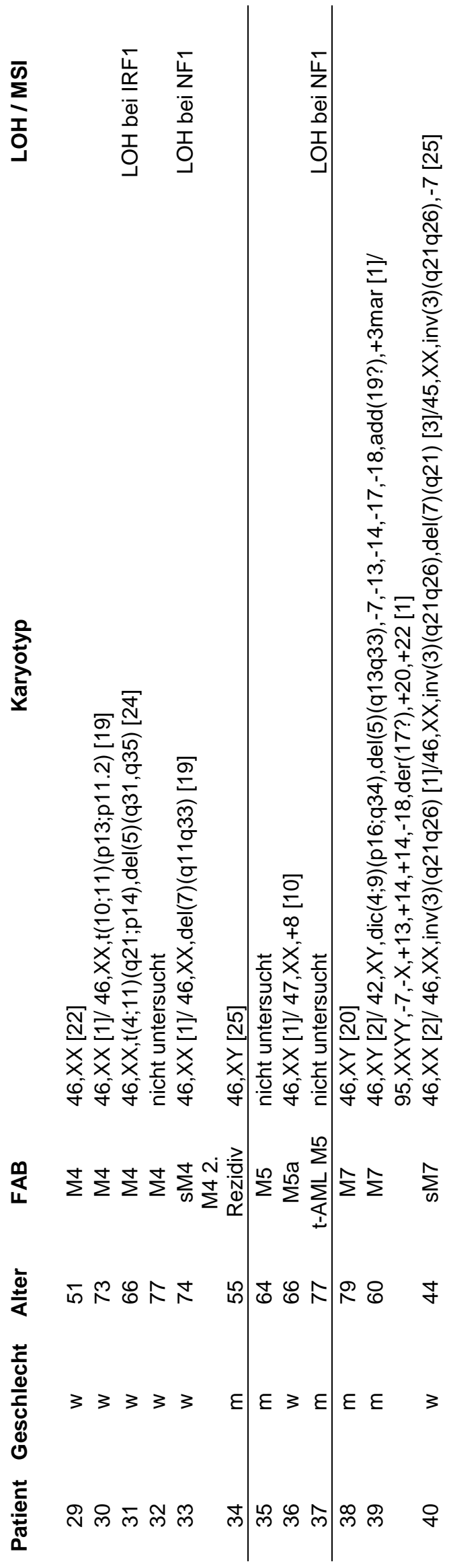




\subsection{Zytogenetik}

\subsubsection{Zytogenetische Befunde}

Bei 37 der 40 Patienten konnten zytogenetische Daten erhoben werden. Dabei zeigten zwei Patienten eine Tetrasomie ohne strukturelle Veränderungen in einem kleinen Anteil der untersuchten Metaphasen. Komplexe Anomalien traten bei 7 Patienten auf (19\%), $\mathrm{t}(15 ; 17)$ bei vier Patienten (alle mit AML M3), Trisomie 8 bei drei Patienten, -7/7q- bei zwei Patienten, $t(6 ; 9)$ und inv 3 jeweils bei einem Patienten. Zwei weitere Patienten hatten verschiedenste chromosomale Alterationen.

\subsubsection{Zytogenetische Befunde in Korrelation zur Mikrosatellitenanalyse}

Von den 37 zytogenetisch untersuchten Patienten wiesen 21 (57\%) chromosomale Anomalien auf. Von den zehn Patienten, die LOH zeigten, hatten sieben einen abnormen und zwei einen normalen Karyotyp; ein Patient war nicht zytogenetisch untersucht worden.

Eine Übereinstimmung der Loci, die von zytogenetischen Veränderungen betroffen waren, und solcher, an denen ein Allelverlust detektiert werden konnte, zeigte sich bei den Patienten 3,7,11,12 und 31. In diesen Fällen fehlte entweder das entsprechende gesamte Chromosom, wie z.B. bei Patient 11 (Chromosom 12 / Marker D12S89) und Patient 12 (Chromosom 17 / Marker NF1), oder nur die jeweilige Region, z.B. bei Patient 7 (del(5)(q11.2) / Marker APC $(5 q 21 / 22))$, bei Patient 3 (del(5)(q22q35) / Marker APC (5q21/22)) und Patient 31 (del(5)(q31,q35) / Marker IRF1 (5q31)). Die Anwendung des exakten Fisher-Tests für kleine Stichproben erbrachte keine signifikant positive Korrelation zwischen chromosomalen Anomalien und der Ausbildung von $\mathrm{LOH}(p=0,141)$.

\section{3 hMSH2-Expression}

\subsubsection{Immunhistochemischer Nachweis der hMSH2-Expression}

Mithilfe immunhistochemischer Färbung wurde die hMSH2-Expression in den Blasten von 15 Patienten mit AML mit einem murinen, monoklonalen Antikörper gegen hMSH2 untersucht. Entsprechend dem prozentualen Anteil der für hMSH2 positiv gefärbten Zellen wurden die Ergebnisse in sechs Gruppen eingeteilt (Tabelle 5). Neun von 15 Patienten (60\%) zeigten weniger als $10 \%$ positiv gefärbte Zellen (Score 1). Bei vier Patienten (27\%) wurde in 11 bis $30 \%$ der Zellen eine Färbung festgestellt (Score 2). Die Zellen von einem weiteren Patienten 
konnten als Score 3 klassifiziert werden (31-50\% positiv gefärbte Zellen). Nur ein Patient entsprach dem Score 5 (71-90\% positiv gefärbte Zellen) und zeigte damit einen hohen Anteil von Blasten mit Expression von hMSH2. Den Scores 4 (51-70\%) und 6 (91-100\%) konnten keine Patienten zugeordnet werden. Insgesamt zeigten $86,7 \%$ der immunhistochemisch untersuchten Patienten weniger als $30 \%$ positiv gefärbte Blasten. Sechs der 15 Patienten zeigten weniger als $5 \%$ gefärbte Blasten entsprechend einer nur geringen hMSH2Expression.
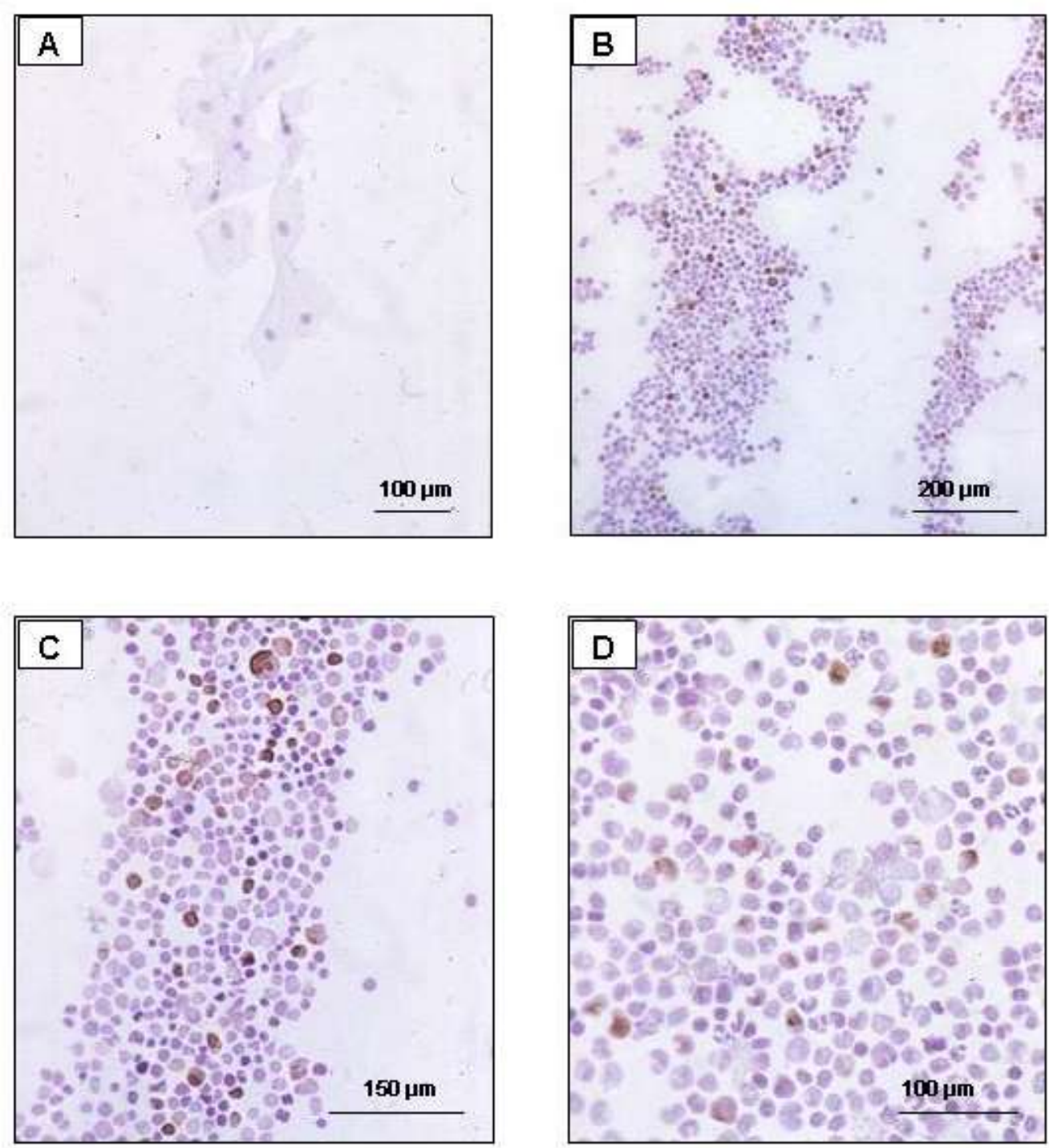

Abbildung 2: Immunhistochemische Untersuchung unter Verwendung eines Primärantikörpers gegen hMSH2.

(A) Bei Bukkalepithelzellen ist keine nukleäre Braunfärbung erkennbar.

(B) + (C) KM-Ausstrich eines Patienten mit sekundärer AML M1, komplex aberrantem Karyotyp und LOH bei NF1. Es zeigt sich bei einem Blastenanteil von insgesamt etwa 45\% ein immunhistochemischer Nachweis des hMSH2-Proteins in circa 15\% der Blasten (Score 2).

(D) KM-Ausstrich einer Patientin mit AML M2, normalem Karyotyp ohne LOH-Nachweis. Bei einem Blastenanteil über $80 \%$ zeigte sich bei weniger als $10 \%$ der Blasten eine immunhistochemisch positive Reaktion für hMSH2. 


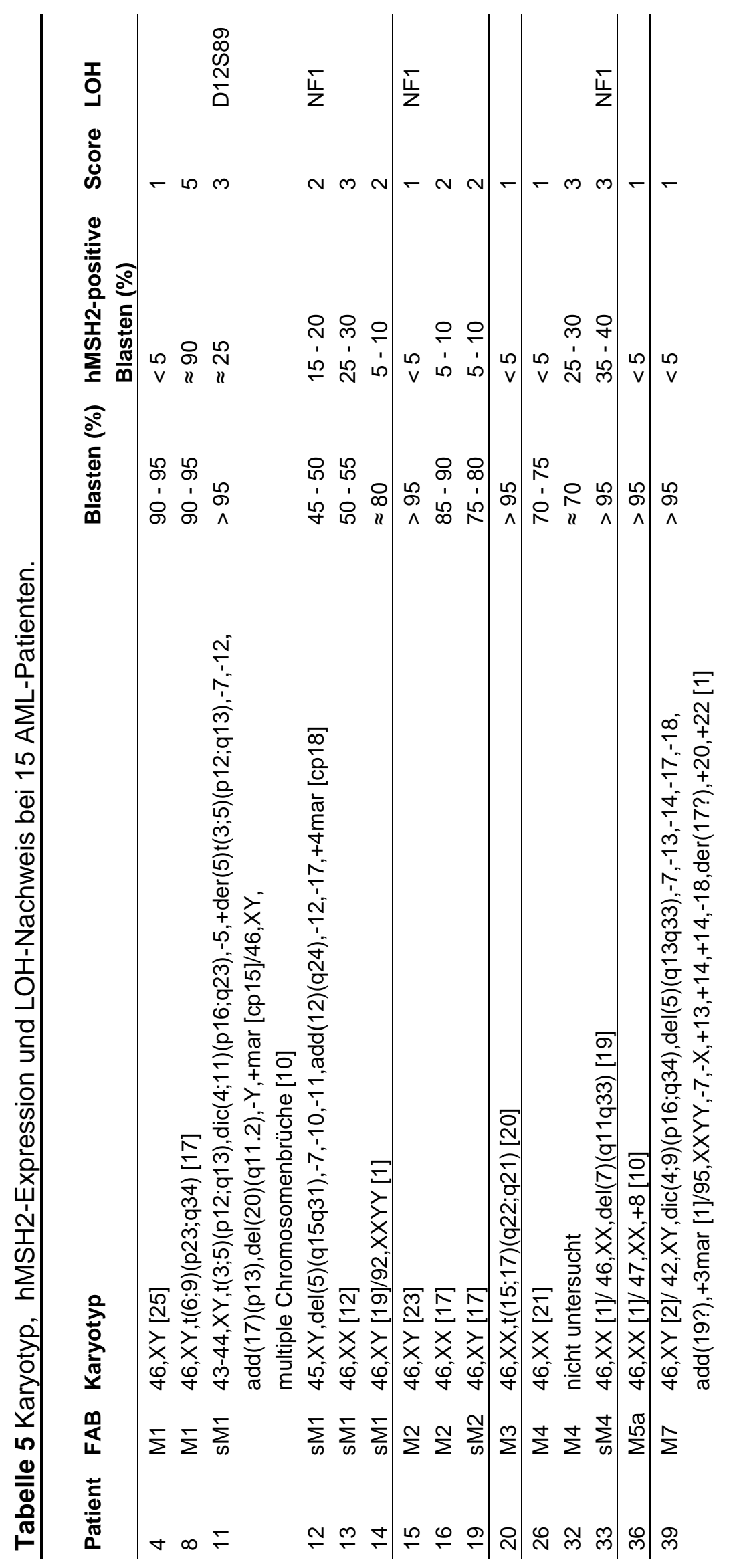




\subsubsection{Nachweis von hMSH2 in AML-Blasten mittels Western Blot}

Die Expression des hMSH2-Proteins in AML-Blasten von 12 Patienten wurde zusätzlich durch Western Blot untersucht. Dabei zeigten 2 der zwölf Patienten (17\%) eine singuläre Protein-Bande bei 100 kD (Abbildung 3), was dem Molekülgewicht des hMSH2-Proteins entspricht. Es handelte sich um einen Patienten mit AML M2 und normalem Karyotyp sowie einen mit therapieinduzierter AML M5, bei dem der Karyotyp nicht bestimmt worden war. Bei beiden Patienten wurde je ein LOH festgestellt (RB1, NF1). Diese Ergebnisse sind in Tabelle 6 zusammengefasst.
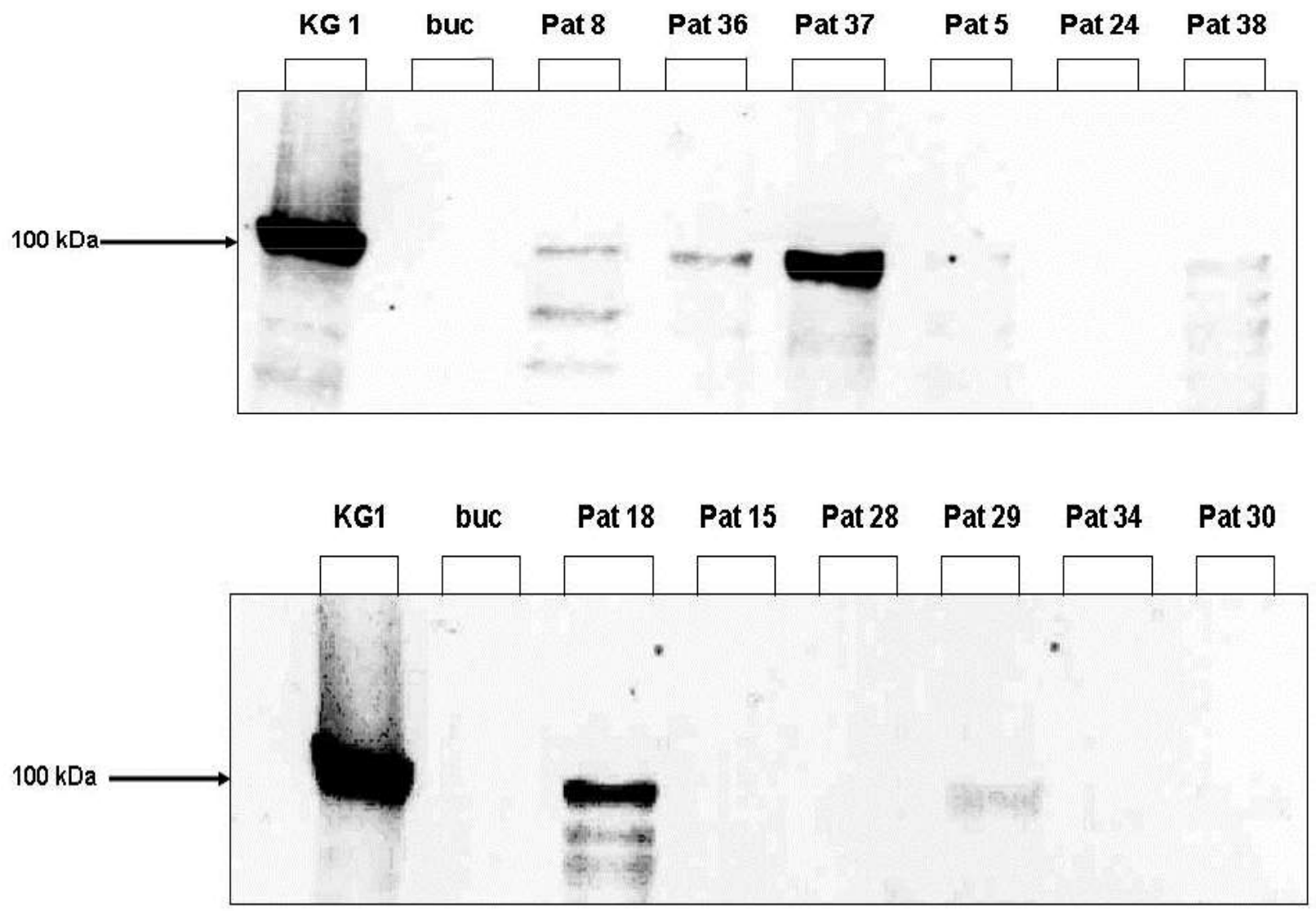

Abbildung 3: hMSH2-Expressionsanalyse mittels Western Blot-Analyse von Zelllysaten aus AML-Blasten von zwölf verschiedenen Patienten. KG1-Zellen repräsentieren die Positiv-, Bukkalepithelzellen die Negativkontrolle. Das Molekulargewicht des hMSH2-Proteins von $100 \mathrm{kDa}$ ist durch Pfeile dargestellt. 


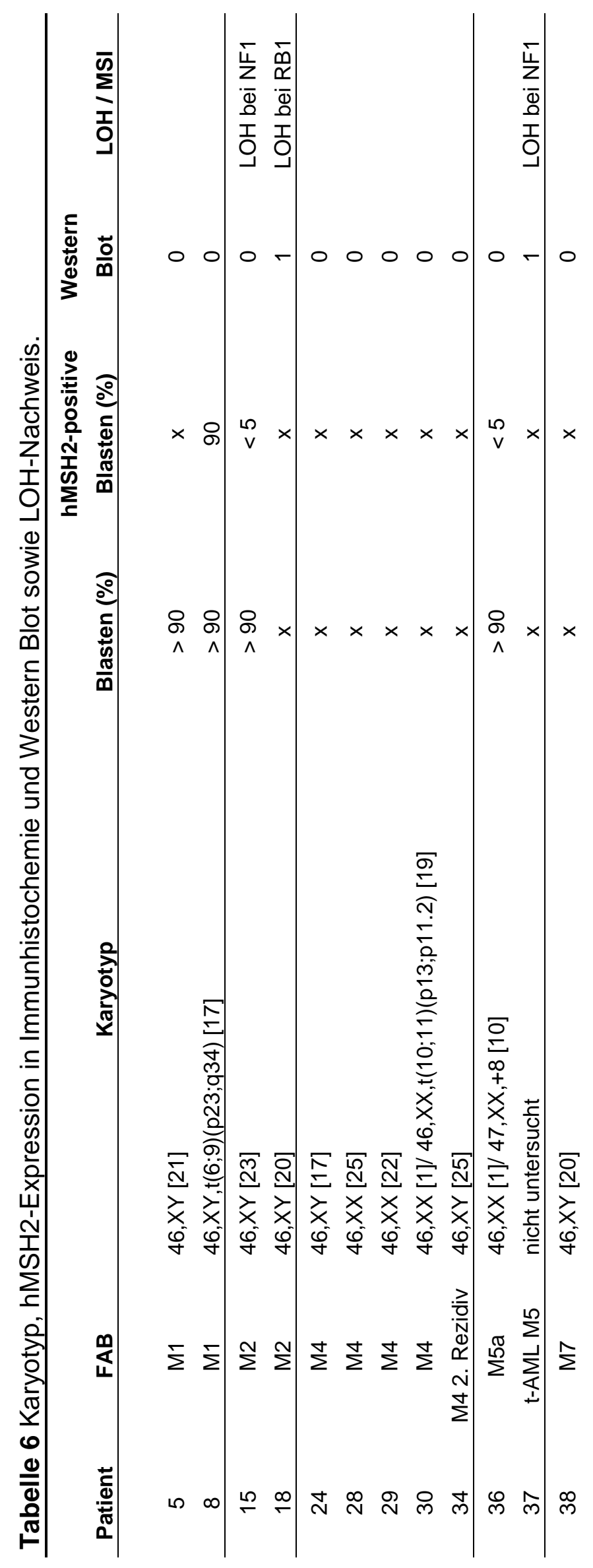




\subsection{3 hMSH2-Expression in Korrelation zur Mikrosatellitenanalyse}

Von den 15 Patienten mit AML, deren Knochenmark-Ausstriche immunhistochemisch untersucht wurden, waren vier von einem Allelverlust betroffen (Tabelle 3). Drei Patienten zeigten diesen beim Marker NF1. Es handelte sich dabei um einen Patienten 1.) mit sekundärer AML M1 klassifiziert als Score 2, 2.) mit AML M2 und einem Score von 1 sowie 3.) mit sekundärer AML M4 (Score 3). Ein LOH bei D12S89 wurde bei einem Patienten mit sekundärer AML M1 und einem Score von 2 detektiert. Alle diese Patienten mit Allelverlust zeigten weniger als $40 \%$ positiv gefärbte Zellen. Umgekehrt ließ sich bei den Patienten mit über $40 \%$ für hMSH2 positiv gefärbten Zellen kein LOH nachweisen. Diese Ergebnisse waren jedoch statistisch nicht signifikant. Bei zwei von zwölf Patienten, deren hMSH2Expression durch Western Blot untersucht wurde, war eine singuläre Protein-Bande bei 100 $\mathrm{kD}$, entsprechend dem Molekulargewicht des hMSH2-Proteins zu verzeichnen. Beide konnten auch einen Allelverlust aufweisen (Marker RB1 und NF1). Umgekehrt war bei den zehn restlichen Patienten ohne Protein-Bande im Western Blot nur einer von LOH betroffen. Es kam also bei den hier untersuchten Patienten, bei denen auch eine geringere hMSH2Expression im Western Blot nachgewiesen wurde, nicht zu vermehrtem Auftreten von LOH.

\subsubsection{Vergleich von hMSH2-Expression mit Ergebnissen der Zytogenetik}

Drei der 15 Patienten mit AML, deren Knochenmark-Ausstriche immunhistochemisch untersucht wurden, zeigten komplexe chromosomale Anomalien. Diese Patienten wurden entsprechend des prozentualen Anteils der positiv gefärbten Zellen, entsprechend einem immunhistochemischen Nachweis des hMSH2-Proteins, als Score 2, 2 und 1 klassifiziert, hatten also weniger als $30 \% \mathrm{hMSH} 2$ positiv gefärbte Blasten. Andererseits konnten sechs Patienten mit normalem Karyotyp wie folgt auf die Scores verteilt werden: 1, 2, 1, 1, 1, 1. Insgesamt zeigte sich keine positive Korrelation einer verminderten hMSH2-Expression mit dem Auftreten chromosomaler Abberationen. 


\section{Diskussion}

Die akute myeloische Leukämie (AML) als häufigste akute Leukämie bei Erwachsenen ist eine maligne hämatologische Erkrankung, die in hämatologischen Stamm- und Vorläuferzellen entsteht. Mit Ausnahme einiger weniger AML-Subtypen haben sich die Grundzüge der Therapie in den letzen 20 Jahren nicht signifikant verändert. Aus diesem Grund bleibt der Therapieerfolg für die Mehrheit der Patienten mit Langzeitüberlebensraten von ca. 20 bis 30\% weiterhin schlecht (Gallipoli et al. 2015). Aus der genetischen Heterogenität ergeben sich mehrere bedeutende klinische Aspekte, da bestimmte chromosomale und molekulargenetische Veränderungen zu den wichtigsten prognostischen Markern zählen und zur Risikostratifizierung bei Therapieentscheidungen herangezogen werden können. Die identifizierten Marker können zur Entwicklung neuer zielgerichteter Therapien genutzt werden (Marcucci et al. 2011).

Zum Zweck der Identifikation des Einflusses zellzyklusregulierender Gene sowie DNAmismatch-repair assoziierter Proteine bei der Entstehung der AML wurden in der vorliegenden Arbeit 40 Patienten mit AML 1.) auf Mikrosatelliteninstabilität sowie 2.) auf die Expression des DNA-mismatch-repair-assoziierten Proteins hMSH2 untersucht. Hierzu wurden 18 Mikrosatelliten-Marker verwendet, welche auf 15 Chromosomenarmen lokalisiert sind.

Dabei konnte LOH bei 10 Patienten (25\%) nachgewiesen werden. Interessanterweise war bei keinem der untersuchten Patienten MSI nachweisbar. Dieses Ergebnis zeigt einen deutlichen Unterschied in der Prävalenz für Mikrosatellitenalterationen im Vergleich zu Patienten mit HNPCC-Syndrom, bei denen mehr als 90\% der Tumore MSI aufweisen können. Aufgrund dieser hohen Rate ist die Mikrosatellitenanalyse bei der Diagnostik des HNPCC-Syndroms ein bereits gebräuchlicher Screening-Test. Sporadische kolorektale Karzinome zeigen andererseits nur in 10-15\% der Fälle MSI (Müller et al. 2004). Da der Nachweis von Mikrosatelliteninstabilität als Hinweis auf ein defizientes DNA-mismatchrepair-System im Sinne eines mutator phenotype gewertet werden kann, lässt dieses Ergebnis den Schluss zu, dass ein defizientes DNA-mismatch-repair-System nicht der einzige Pathomechanismus in der Genese der AML sein kann. Hierfür spricht ebenfalls die ausgeprägte genetische Heterogenität der Erkrankung.

Die Ergebnisse der vorliegenden Arbeit stehen im Gegensatz zu den Analysen von Nakanishi et al. (2001), welche über den Nachweis von MSI bei über $84 \%$ bei Patienten mit AML berichteten, die der Strahlung einer Atombombe ausgesetzt waren, im Gegensatz zu einer Rate von $8,3 \% \mathrm{MSI}$ bei nicht der Strahlung exponierten an AML Erkrankten. Diese 
extrem hohe Rate bezog sich auf Patienten, die ihre Erkrankung 41 - 49 Jahre nach Strahlenexposition entwickelten. Die höchste Inzidenz bestand sieben Jahre nach Exposition. Hierzu gab es keine Mikrosatellitenanalysen. Der fehlende Nachweis von MSI bei den Patienten der vorliegenden Arbeit könnte auf eine genetische Schädigung von geringerer zeitlicher Latenz bis zum Krankheitsbeginn hindeuten.

Unter der Annahme der genetischen Instabilität bei AML im Sinne eines mutator phenotype, käme es nach Inaktivierung von Genen, die für die genomische Stabilität einer Zelle verantwortlich sind, zu einer Akkumulation von Mutationen, von denen eine enorme Anzahl in repetitiven Gensequenzen zu finden ist (Loeb 1998). Es ist zu vermuten, dass zumindest bei einem Teil der Patienten eine Akkumulation von Mutationen dieser Art erst über einen längeren Zeitraum entsteht bzw. weitere Einflussfaktoren erforderlich sind.

Diese These wird unterstützt durch die Ergebnisse von Das-Gupta et al. (2001), bei denen von 71 untersuchten Patienten mit AML neun (13\%) MSI aufwiesen. Diese neun Patienten hatten entweder eine therapieassoziierte AML oder waren älter als 60 Jahre. Umgekehrt war bei keinem Patienten unter 60 Jahre mit de novo-AML MSI zu detektieren. In einer Untersuchung von Tasaka (1997) konnte gezeigt werden, dass die Detektionsrate von MSI bei Patienten mit AML während des Krankheitsprogresses zunimmt. Die höchste Rate von 35\% zeigte sich zum Zeitpunkt des Rezidivs. Dies legt die Vermutung nahe, dass das Auftreten von MSI bei AML möglicherweise ein spätes Ereignis im Krankheitsverlauf ist. Die Tatsache, dass in der vorliegenden Arbeit die Mikrosatellitenanalyse bei fast allen Patienten zum Zeitpunkt der Diagnosestellung erfolgte, könnte eine Ursache für den fehlenden Nachweis von MSI sein.

So berichten Rimsza et al. (2000) ebenfalls von einem fehlenden Nachweis von MSI bei AML, passend zu den Ergebnissen der vorliegenden Arbeit. Jedoch unterscheidet sich das dort untersuchte Patientenkollektiv durch einen höheren Anteil an sekundären Leukämien und Rezidiven, bei dem vermehrt MSI zu erwarten gewesen wären. Hier könnte sich die geringe Anzahl der dort untersuchten Mikrosatelliten von nur drei Loci ausgewirkt haben.

Das in der gegenwärtigen Literatur insgesamt doch sehr heterogene Bild bezüglich des Nachweises von MSI bei AML spiegelt wohl am ehesten die Wahl der verwendeten Primer wider, mit denen die Patientengruppen untersucht wurden. Um ein passendes Panel an Primern von diagnostischem Wert und aussagekräftiger Risikoabschätzung zur Verfügung zu haben, werden zukünftig weitere Untersuchungen von Mikrosatellitenloci notwendig sein. 
Bei 10 Patienten (25\%) konnte in dieser Arbeit LOH nachgewiesen werden. Dies ist insofern interessant, als eine aktuelle Studie die signifikante prognostische Relevanz von LOH bei AML-Patienten belegen konnte (Gronseth et al. 2015). Patienten mit copyneutralen LOH zeigten nicht nur eine kürzere Dauer der kompletten Remission und ein schlechteres Gesamtüberleben, sondern der Nachweis von LOH erwies sich auch als unabhängiger prädiktiver Marker für ein früheres Rezidiv.

Die hohe Detektionsrate von LOH im Vergleich zu MSI in der vorliegenden Arbeit korreliert mit den Ergebnissen von Pabst et al. (1996). Hier konnte gezeigt werden, dass von 114 erwachsenen Patienten mit akuter Leukämie 81 LOH aufweisen, bezüglich der AML 25 von 32 (78,1\%), jedoch nur 10 der insgesamt 114 Patienten Mikrosatelliteninstabilität zeigte. Zu ähnlichen Resultaten kamen auch Maeck et al. (2000) bei der Untersuchung von Patienten mit MDS. Auch hier zeigte sich ein deutlich häufigeres Vorkommen von LOH mit $23 \% \mathrm{im}$ Vergleich zu MSI, welche nur in $8 \%$ der Fälle detektiert werden konnte.

Überraschenderweise konnte in der vorliegenden Arbeit unter Anwendung des exakten Fisher-Tests für kleine Stichproben keine signifikant positive Korrelation zwischen chromosomalen Anomalien und der Ausbildung von LOH gezeigt werden. Dies zeigt Ähnlichkeiten zu den Ergebnissen von Serrano et al. (2008) bei denen 22 AML-Patienten mit normalem Karyotyp untersucht wurden. Hier zeigte sich eine Quote von 22,7\% für das Auffinden von LOH. Dies legt die Vermutung nahe, dass es sich bei LOH bei Patienten mit AML um eine erworbene uniparentale Disomie handeln könnte (Gorletta et al. 2005, Serrano et al. 2008).

Andererseits wies die überwiegende Zahl der Patienten, bei denen LOH nachgewiesen werden konnten, Karyotypveränderungen auf, auch wenn dies statistisch nicht signifikant war. Bei zwei der Patienten konnten jeweils zwei LOHs nachgewiesen werden. Diese zeigten ebenfalls jeweils einen sehr komplex aberranten Karyotyp. Bei jedem dieser beiden Patienten war auch der Marker APC betroffen. Das APC-Gen ist bei Patienten mit familiärer adenomatöser Polyposis sowie auch bei sporadisch auftretenden kolorektalen Karzinomen mutiert. Sein Genprodukt ist ein zytoplasmatisches Protein, das zellzyklusregulierende Funktionen erfüllt. APC als Tumorsuppressor-Gen konnte auch bei Patienten mit Tumoren in Magen und Pankreas mutiert gefunden werden (Senda et al. 2005).

Dies ist insofern interessant, als Stoddart et al. (2014) zeigen konnten, dass bei Verlust von TP53 in hämatopoetischen Stamm- und Vorläuferzellen, eine Haploinsuffizienz für Egr1 und APC bei Mäusen in 17\% der Fälle zur Entwicklung einer AML führt. Bei einem der Patienten 
der vorliegenden Arbeit mit jeweils zwei nachgewiesenen LOH war der Marker TP53 ebenfalls betroffen. Weitere Untersuchungen sind jedoch erforderlich, um zu klären, ob dieser Zusammenhang beim Menschen ebenfalls von pathogenetischer Relevanz ist.

Auffällig war außerdem, dass der Marker NF1 bei fünf der zehn von $\mathrm{LOH}$ betroffenen Patienten und damit bei $50 \%$ der LOH beteiligt war. Auf die Gesamtzahl der untersuchten Patienten bezogen war der Marker NF1 somit bei immerhin 12,5\% aller 40 AML-Patienten auffällig. Bekannt ist, dass Keimbahnalterationen des Tumorsuppressor-Gens NF1 zur Neurofibromatose Typ 1 führen. Hierbei ist das Risiko für die Entwicklung einer myelomonozytären Leukämie bzw. AML deutlich erhöht (Boudry-Labis et al. 2013).

Der Nachweis von Deletionen beim Marker NF1 bei Patienten mit AML, welche nicht an Neurofibromatose erkrankt sind, korreliert mit Ergebnissen anderer Arbeitsgruppen, die Anteile von 3,5 bis 7,3\% (Boudry-Labis et al. 2013, Haferlach et al. 2012, Parkin et al. 2010) nachweisen konnten. Jedoch zeigt sich der Anteil von Deletionen beim Marker NF1 in der vorliegenden Arbeit deutlich höher.

In einer aktuellen Untersuchung konnte gezeigt werden, dass eine NF1-Suppression bei Haploinsuffizienz von MLL3 auf Chromosom 7 und Defizienz von P53 zur Entwicklung einer AML führt (Will et al. 2014). In der vorliegenden Arbeit standen bei vier der fünf Patienten mit LOH am Marker NF1 Analysen der Zytogenetik zur Verfügung, in der zwei Patienten ebenfalls eine Deletion auf Chromosom 7 zeigten. Bezüglich der beiden anderen Patienten ist eine Alteration auf submikroskopischer Ebene möglich, was den diagnostischen Stellenwert molekulargenetischer Untersuchungen unterstreicht.

2013 zeigten Boudry-Labis et al. eine signifikante Assoziation zwischen einer NF1-Deletion und einer prognostisch ungünstigen Zytogenetik sowie einem monosomalen Karyotyp. Dahingegen korrelierten diese Daten nicht mit Geschlecht, Alter oder der Verteilung auf die FAB-Subtypen. Eine signifikante Korrelation zu den genannten Faktoren ließ sich in der vorliegenden Arbeit jedoch weder ableiten noch ausschließen, da die Anzahl der betroffenen Patienten für eine Auswertung zu gering war. Auffällig war jedoch, dass drei dieser fünf Patienten mit einem LOH bei NF1 an einer sekundären AML erkrankt waren. Dies legt die Vermutung nahe, dass es sich bei NF1-Deletionen auch um erworbene sekundäre Ereignisse handeln könnte, wie Boudry-Labis et al. (2013) ebenfalls schlussfolgerten.

Die Rolle von NF1 bei malignen myeloischen Erkrankungen ist bisher noch wenig untersucht. Bekannt ist, dass das Genprodukt von NF1 als negativer Regulator von RAS 
fungiert (Haferlach et al. 2012, Parkin et al. 2010). Ein Funktionsverlust von NF1 entspricht funktionell einer aktivierenden Mutation von RAS. Alterationen von RAS führen zu Veränderungen von RAS abhängigen Signalwegen wie beispielsweise FLT3, KIT oder CBL. Weiterhin konnte gezeigt werden, dass die Häufigkeit von NF1-Deletionen bei Patienten mit komplex aberrantem Karyotyp mit 30,6\% deutlich höher lag als bei Patienten mit normalem Karyotyp (1,2\%) und dass akute myeloische Leukämien mit RUNX1-RUNX1T1Veränderungen, also mit Mutationen eines Transskriptionsfaktors, der die Differenzierung der hämatopoetischen Stammzelle reguliert, mit einer niedrigen NF1-Expression assoziiert sind. Daten, die mithilfe von zellbasierten In-vitro-Assays erhoben wurden, legten die Vermutung nahe, dass eine NF1-Defizienz zur Resistenz für eine Therapie mit AraC führt (Haferlach et al. 2012).

Andererseits vermuteten Parkin et al. (2010) aufgrund der negativ regulierenden Wirkung von NF1 auf mTOR, dass AML-Blasten mit NF1-Defizienz eine größere Abhängigkeit von der Signaltransduktion durch mTOR aufweisen als NF1-Wildtyp-Blasten. So konnten sie durch Messung der Induktion von Apoptose nachweisen, dass AML-Blasten ohne funktionsfähiges NF1 signifikant empfindlicher auf eine Behandlung mit Rapamycin reagierten als NF1Wildtyp-Blasten.

Insgesamt weist die in der vorliegenden Arbeit relativ hohe Rate von NF1-Deletionen bei AML auch im Kontext mit den o.g. Ergebnissen anderer Arbeitsgruppen auf die noch ungeklärte pathogenetische Relevanz dieser Alteration hin. Weitere Untersuchungen sind notwendig, um auch die klinischen Möglichkeiten zielgenauerer Therapieoptionen entsprechend dem NF1-Status zu eruieren.

Zur Klärung der Frage, inwieweit genetische Instabilität bei der AML als Folge eines defekten DNA-mismatch-repair-Systems auftritt, wurden ergänzend die Expressionsmuster des MMRassoziierten hMSH2-Proteins untersucht und mit den Ergebnissen der Mikrosatellitenanalyse verglichen. Hierzu wurden bei 15 der 40 Patienten immunhistochemische Färbungen an Knochenmarkausstrichen durchgeführt und zusätzlich bei 12 Patienten mittels Western Blot die Expression von hMSH2 getestet.

Insgesamt zeigte sich bei den jeweils untersuchten Patienten eine geringgradige Expression von hMSH2. So war bei den 12 mittels Western Blot untersuchten Patienten bei nur zwei Patienten (17\%) eine Expression des hMSH2-Proteins nachweisbar. In der immunhistochemischen Färbung war lediglich bei einem Patienten eine starke hMSH2Expression (90\% positive Blasten) zu verzeichnen. Sechs der 15 Patienten (40\%) zeigten 
weniger als 5\% gefärbte Zellen. Wenngleich die Ergebnisse der vorliegenden Arbeit aufgrund der begrenzten Anzahl untersuchter Patienten keine endgültige Schlussfolgerung zulassen, liegt doch die Vermutung nahe, dass eine verminderte Expression von hMSH2 zumindest bei einem Teil der Patienten mit AML pathogenetische Relevanz hat.

Das DNA-mismatch-repair-System dient der Aufrechterhaltung der genetischen Stabilität. Eine Defizienz dieses Systems führt zum Auftreten des mutator phenotype mit Akkumulation von Mutationen in Onkogenen und Tumorsuppressor-Genen. MSH2 ist eins der dem MMRSystem angehörenden Gene. Beim HNPCC-Syndrom sowie auch anderen menschlichen Tumoren ist hMSH2 direkt an der Entstehung von Mikrosatelliteninstabilität und der Tumorgenese beteiligt (Zhu et al. 1999).

Die Tatsache, dass sich in der vorliegenden Arbeit statistisch kein Zusammenhang zwischen MSH2-Expression und Karyotyp-Alterationen nachweisen ließ, könnte daraufhin hindeuten, dass der Expressionsverlust von hMHS2 ein eher spätes genetisches Ereignis sein könnte. So konnten Mao et al. 2008 nachweisen, dass eine Defizienz des mismatch-repair-Systems (MMR) zwar in allen Stadien der AML auftreten kann, der prozentuale Anteil bei Patienten bei Therapieresistenz oder Rezidiv jedoch deutlich höher liegt. Dies lässt den Schluss zu, dass ein Funktionsverlust des MMR-Systems das Auftreten von Resistenzen bzw. Rezidiven begünstigen kann.

Die Ergebnisse der vorliegenden Arbeit konnten zeigen, dass eine verminderte Expression von hMSH2 nicht mit einem vermehrten Auftreten von Mikrosatelliteninstabilität einhergehen muss. Es liegt die Vermutung nahe, dass sich eine Mikrosatelliteninstabilität bei MMRDefizienz häufig erst im weiteren Krankheitsverlauf manifestiert. Diese Hypothese wird unterstützt durch die Beobachtung von Sheikhha et al. (2002), dass die Rate von Replikationsfehlern bei Patienten mit Therapie assoziierter bzw. sekundärer AML mit über $40 \%$ signifikant höher lag als ihr Anteil bei neu diagnostizierter AML von nur 20,5\%. Vergleicht man diese Ergebnisse mit denen der vorliegenden Arbeit, so zeigt sich in letzterer ebenfalls ein Anteil von über 44\% (4 von 9 Patienten) für das Auftreten von LOH bei sekundärer bzw. Therapie assoziierter AML im Vergleich zu 19,4\% (6 von 31) bei Patienten mit de-novo-AML.

Dennoch ist die Kenntnis einer MMR-Defizienz von nicht zu unterschätzender Bedeutung. So berichten Clodfelter et al. (2005) von einer Therapie-Resistenz MMR defizienter Zellen auf Cisplatin unabhängig vom Auftreten eines mutator phenotype. Im Verlauf entwickelte sich dann eine medikamenteninduzierte genetische Instabiliät. So konnte eine einzige 
Punktmutation zur genetischen Instabilität einerseits oder zu einer erhöhten Überlebensrate andererseits nach Cisplatin-Exposition beitragen. Diese erworbene Chemotoleranz bei MSH2-Mutation verdeutlicht die noch nicht abschätzbare Relevanz solcher Defekte unter therapeutischen Aspekten.

Auch wenn ein Defekt des hMSH2 bei der AML möglicherweise nicht die gleiche direkte pathogenetische Relevanz aufweist wie beim HNPCC-Syndrom, so unterstreicht die Beobachtung von Mao et al. (2008), dass MMR-Defekte bei Rezidiven signifikant häufiger nachzuweisen sind als bei frisch diagnostizierten AML-Erkrankungen, den Stellenwert weiterer Untersuchungen des MMR-Systems im Hinblick auf eine Mitbeteiligung an der Rezidiventstehung.

Abschließend kann gesagt werden, dass die Mikrosatellitenanalyse eine gute Möglichkeit bietet, AML-Patienten auf das Vorhandensein von MSI und LOH zu untersuchen, da es die Detektion kleinerer chromosomaler Deletionen erlaubt, die einer konventionellen zytogenetischen Diagnostik entgehen würden. Weitere Untersuchungen sind jedoch erforderlich, um ein standardisiertes Primer-Panel zusammen zu stellen, welches in der Routinediagnostik zur weiteren Klassifizierung, Risikostratifizierung und Rezidiverkennung eingesetzt werden kann. Schließlich könnten in Kenntnis spezifischer Marker zielgerichtete Therapien zum Einsatz kommen, die die Prognose in Zukunft verbessern könnten. 


\section{Zusammenfassung}

Die akute myeloische Leukämie als häufigste akute Leukämie bei Erwachsenen ist eine maligne, hämatologische, genetisch heterogene, klonale Erkrankung, die ihren Ursprung in hämatologischen Stamm- und Vorläuferzellen hat, in denen durch Anhäufung erworbener genetischer Veränderungen die Mechanismen von Selbsterneuerung, Proliferation und Differenzierung gestört werden. Chromosomale und molekulargenetische Veränderungen zählen zu den wichtigsten prognostischen Markern und könnten zur Entwicklung neuer zielgerichteter Therapien genutzt werden. Zum Zweck der Identifikation des Einflusses zellzyklusregulierender Gene sowie DNA-mismatch-repair-assoziierter Proteine bei der Entstehung der AML wurden in der vorliegenden Arbeit Knochenmarkaspirate von 40 Patienten mit AML auf Mikrosatelliteninstabilität sowie die Expression des DNA-mismatchrepair-assoziierten Proteins hMSH2 untersucht.

Interessanterweise konnte bei keinem der 40 Patienten MSI nachgewiesen werden. LOH war bei $25 \%$ der Patienten nachweisbar. Hierbei war ein Anteil von über $44 \%$ für das Auftreten von LOH bei sekundärer bzw. therapieassoziierter AML im Vergleich zu 19,4\% bei Patienten mit de-novo-AML nachweisbar. Auffallend hoch war dabei der Anteil des Markers NF1 mit $50 \%$ der nachgewiesenen LOH. Beim überwiegenden Teil der Patienten zeigte sich eine niedrige Expression von hMSH2. Eine Korrelation von verminderter hMSH2-Expression mit Karyotypveränderungen oder Mikrosatelliteninstabilität war nicht nachzuweisen.

Der fehlende Nachweis von MSI im untersuchten Patientenkollektiv deutet daraufhin, dass Mikrosatelliteninstabilität nicht der einzige Pathomechanismus in der Genese der AML ist. Auch die verminderte Expression des hMSH2-Proteins, welche sich sowohl im Knochenmark-Bröckelausstrich immunhistochemisch als auch im Western Blot zeigte, ist aufgrund mangelnder Korrelation mit Karyotypveränderungen oder LOH nur als Teilaspekt in der Pathogenese der AML zu deuten. Das vermehrte Auftreten von $\mathrm{LOH}$ bei der sekundären AML im Vergleich zur de-novo-AML legt die Vermutung nahe, dass es sich hierbei um ein eher spätes bzw. therapieinduziertes genetisches Ereignis handelt. Der auffallend hohe Anteil von LOH beim Marker NF1 dürfte ein lohnenswertes Ziel weiterer Untersuchungen darstellen. 


\section{Literaturverzeichnis}

Bennett JM, Catovsky D, Daniel MT, Flandrin G, Galton DA, Gralnick HR, Sultan C (1985): Proposed revised criteria for the classification of acute myeloid leukemia. A report of the French-American-British Cooperative Group. Ann Intern Med 103, 620-625

Boudry-Labis E, Roche-Lestienne C, Nibourel O, Boissel N, Terre C, Perot C, Eclache V, Gachard N, Tigaud I, Plessis G et al. (2013): Neurofibromatosis-1 gene deletions and mutations in de novo adult acute myeloid leukemia. Am J Hematol $\underline{88}, 306-311$

Bova GS, Carter BS, Bussemakers MJG, Emi M, Fujiwara Y, Kyprianou N, Jacobs SC, Robinson JC, Epstein JI, Walsh PC et al. (1993): Homozygous deletion and frequent allelic loss of chromosome 8p22 loci in human prostate cancer. Cancer Res $\underline{53}, 3869-3873$

Bradford MM (1976): A rapid and sensitive method for the quantification of microgram quantities of protein utilizing the principle of protein dry banding. Anal Biochem $\underline{72}, 246-254$

Budowle B, Chakraborty R, Giusti AM, Eisenberg AJ, Allen RC (1991): Analysis of the VNTR locus D1S80 by the PCR followed by high-resolution PAGE. Am J Hum Genet $\underline{48}, 137-144$

Clodfelter JE, Gentry MB, Drotschmann K (2005): MSH2 missense mutations alter cisplatin cytotoxicity and promote cisplatin-induced genome instability. Nucleic Acids Res $\underline{33}, 3323-$ 3330

Coppes MJ, Campbell CE, Williams BRG (1993): The role of WT1 in Wilms tumorigenesis. FASEB J $\underline{7}, 886-895$

Das-Gupta EP, Seedhouse CH, Russell NH (2001): Microsatellite instability occurs in defined subsets of patients with acute myeloblastic leukaemia. Br J Haematol 114, 307-312

Deschler B, Lübbert M (2006): Acute myeloid leukemia: epidemiology and etiology. Cancer $\underline{107}, 2099-2107$

Döhner H, Estey E, Amadori S, Appelbaum FR, Büchner T, Burnett AK, Dombret H, Fenaux P, Grimwade D, Larson RA (2010): Diagnosis and management of acute myeloid leukemia in adults: recommendations from an international expert panel, on behalf of the European 
LeukemiaNet, Blood $\underline{115}, 453-474$

Fearon ER, Cho KR, Nigro JM, Kern SE, Simons JW, Ruppert JM, Hamilton SR, Preisinger AC, Thomas G, Kinzler KW (1990): Identification of a chromosome 18q gene that is altered in colorectal cancers. Science $\underline{247}, 49-56$

Figueroa ME, Lugthart S, Li Y, Erpelinck-Verschueren C, Deng X, Christos PJ, Schifano E, Booth J, Putten W, Skrabanek L et al. (2010): DNA Methylation Signatures Identify Biologically Distinct Subtypes in Acute Myeloid Leukemia. Cancer Cell 17(1), 13-27

Fishel, R., Lescoe, M. K., Rao, M. R., Copeland, N. G., Jenkins, N. A., Garber, J., Kane, M., Kolodner, R. (1993): The human mutator gene homolog MSH2 and its association with hereditary nonpolyposis colon cancer. Cell $\underline{75}, 1027-1038$

Gallipoli P, Giotopoulos G, Huntly BJ (2015) Epigenetic regulators as promising therapeutic targets in acute myeloid leukemia. Ther Adv Hematol $\underline{6}$, 103-119

Gorletta TA, Gasparini P, D’Elios MM, Trubia M, Pelicci PG, Di Fiore PP (2005): Frequent loss of heterozygosity without loss of genetic material in acute myeloid leukemia with a normal karyotype. Genes Chromosomes Cancer 44, 334-337

Gregg RG, Couch F, Hogan K, Powers PA (1993): Assignment of the human gene for the alpha 1 subunit of the skeletal muscle DHP-sensitive Ca2+ channel (CACNL1A3) to chromosome 1q31-q32. Genomics $\underline{15}$, 107-112

Gronseth CM, McElhone SE, Storer BE, Kroeger KA, Sandhu V, Fero ML, Appelbaum FR, Estey EH, Fang M (2015): Prognostic significance of acquired copy-neutral loss of heterozygosity in acute myeloid leukemia. Cancer 121, 2900-2908

Haase D, Fonatsch C, Freund M, Wörmann B, Bodenstein H, Bartels H, Stollmann-Gibbels B, Lengfelder E (1995): Cytogenetic findings in 179 patients with myelodysplastic syndromes. Ann Hematol $\underline{70}$, 171-187

Haber DA, Buckler AJ, Glaser T, Call KM, Pelletier J, Sohn RL, Douglass EC, Housman DE (1990): An internal deletion within an 11p13 zinc finger gene contributes to the development of Wilms' tumor. Cell $\underline{61}, 1257-1269$ 
Haferlach C, Grossmann V, Kohlmann A, Schindela S, Kern W, Schnittger S, Haferlach T (2012): Deletion of the tumor-suppressor gene NF1 occurs in $5 \%$ of myeloid malignancies and is accompanied by a mutation in the remaining allele in half of the cases. Leukemia $\underline{26}$, 834-839

Hall JM, Friedman L, Guenther C, Lee MK, Weber JL, Black DM, King MC (1992): Closing in on a breast cancer gene on chromosome 17q. Am J Hum Genet $\underline{50}$, 1235-1242

Herold G: Innere Medizin. Gerd Herold (Verlag), Köln 2015

ISCN 1995: An international system for human cytogenetic nomenclature. S. Karger, Basel 1995

Jiricny J (2006): The multifaceted mismatch-repair system. Nat Rev Mol Cell Biol $\underline{7}$, 335-346

Jones MH, Nakamura Y (1992): Detection of loss of heterozygosity at the human TP53 locus using a dinucleotide repeat polymorphism. Genes Chromosomes Cancer $\underline{5}$, 89-90

Kern W, Behre G, Schilling C, Haferlach T, Adorf D, Jehn U, Waterhouse C, Brack N, Schnittger S, Petrides PE, Hiddemann W: Akute myeloische Leukämie (AML) beim Erwachsenen. In: Hiddemann W, Haferlach T (Hrsg.): Manual Leukämien, myelodysplastische und myeloproliferative Syndrome. 2. Auflage; Tumorzentrum München und W. Zuckschwerdt Verlag, München 2003, 17-48

Knudson AG (1993): Antioncogenes and human cancer. Proc Natl Acad Sci 90, 1091410921

Lazaro C, Gaona A, Xu G, Weiss R, Estivill X (1993): A highly informative CA/GT repeat polymorphism in intron 38 of the human neurofibromatosis type 1 (NF1) gene. Hum Genet 92, 429-430.

Lengauer C, Kinzler KW, Vogelstein B (1998): Genetic instabilities in human cancers. Nature 396, 643-649

Liu B, Parsons R, Papadopoulos N, Nicolaides NC, Lynch HAT, Watson P, Jass, JR, Dunlop M, Wyllie A, Peltomazi P et al. (1996): Analysis of mismatch repair genes in hereditary nonpolyposis colorectal cancer patients. Nat Med 2, $169-174$ 
Loeb LA (1998): Cancer cells exhibit a mutator phenotype. Adv Cancer Res $\underline{72}, 25-56$

Maeck L, Haase D, Schoch C, Hiddemann W, Alves F (2000a): Genetic instability in myelodysplastic syndrome: detection of microsatellite instability and loss of heterozygosity in bone marrow samples with karyotype alterations. $\mathrm{Br} \mathrm{J}$ Haematol $\underline{109}, 842-846$

Maeck L, Kohaus P, Haase D, Hiddemann W, Alves F (2000b): Differential cellular expression of the human MSH2 protein in normal and myelodysplastic haematopoiesis. $\mathrm{Br} \mathrm{J}$ Haematol $\underline{111}, 650-655$

Mao G, Yuan F, Absher K, Jennings CD, Howard DS, Jordan CT, Gu L (2008): Preferential loss of mismatch repair function in refractory and relapsed acute myeloid leukemia: potential contribution to AML progression. Cell Res $\underline{18}, 281-289$

Marcucci G, Haferlach T, Döhner H (2011): Molecular genetics of adult acute myeloid leukemia: Prognostic and therapeutic implications. J Clin Oncol 29(5), 475-486

Modrich P, Lahue R (1996): Mismatch repair in replication fidelity, genetic recombination, and cancer biology. Annu Rev Biochem 65, 101-133

Müller A, Edmonston TB, Dietmaier W, Büttner R, Fishel R, Rüschoff J (2004): MSI-testing in hereditary non-polyposis colorectal carcionoma (HNPCC). Dis Markers 므, 225-236

Murati A, Brecqueville M, Devillier, Mozziconacci M-J, Gelsi-Boyer V, Birnbaum D (2012): Myeloid malignancies: mutations, models and management. BMC Cancer $\underline{12}, 304$

Nakanishi M, Tanaka K, Takahashi T, Kyo T, Dohy H, Fujiwara M, Kamada N: Microsatellite instability in acute myelocytic leukaemia developed from A-bomb survivors. Int $\mathrm{J}$ Radiat Biol $\underline{77}, 687-694$

O'Donnell MR, Abboud CN, Altman J, Appelbaum FR, Arber DA, Attar E, Borate U, Coutre SE, Damon LE, Goorha S (2012): Acute Myeloid Leukemia. J Natl Compr Canc Netw 2012;10, 984-1021

Oliveira EJ, Padua JG, Zucchi MI, Vencovsky R, Vieira MLC (2006): Origin, evolution and genome distribution of microsatellites. Genet Mol Biol $\underline{29}$, 294-307 
Pabst T, Schwaller J, Bellomo MJ, Oestreicher M, Mühlematter D, Tichelli A, Tobler A, Fey MF: Frequent clonal loss of heterozygosity but scarcity of microsatellite instability at chromosomal breakpoint cluster regions in adult leukemias. Blood $\underline{88}, 1026-1034$

Papadopoulos N (1995): Mutations of GTBP in genetically unstable cells. Science $\underline{268}, 1915-$ 1917

Parkin B, Ouillette P, Wang Y, Liu Y, Wright W, Roulston D, Purkayastha A, Dressel A, Karp J, Bockenstedt $P$ et al. (2010): NF1 inactivation in adult acute myelogenous leukemia. Clin Cancer Res $\underline{16}$, 4135-4147

Peltomäki P (2001): Deficient DNA mismatch repair: a common etiologic factor for colon cancer. Hum Mol Genet $\underline{10}, 735-740$

Peltomäki P (2003): Role of DNA mismatch repair defects in the pathogenesis of human cancer. J Clin Oncol. 21(6), 1174-1179

Peltomäki P, Lothe RA, Aaltonen LA, Pylkkänen L, Nyström-Lahti M, Seruca R, David L, Holm R, Ryberg D, Haugen A (1993): Microsatellite instability is associated with tumors that characterize the hereditary non-polyposis colorectal carcinoma syndrome. Cancer Res $\underline{53}$, 5853-5855

Rimsza LM, Kopecky KJ, Ruschulte J, Chen IM, Slovak ML, Karanes C, Godwin J, List A, Willman CL (2000): Microsatellite instability is not a defining genetic feature of acute myeloid leukemogenesis in adults: results of a retrospective study of 132 patients and review of the literature. Leukemia 14, 1044-1051

Risio M, Reato G, Francia di Celle P, Fizzotti M, Rossini FP and Foa R (1996): Microsatellite instability is associated with the histological features of the tumor in nonfamilial colorectal cancer. Cancer research $\underline{56}, 5470-5474$

Riva L, Luzi L, Pelicci PG (2012): Genomics of acute myeloid leukemia: the next generation. Front Oncol. 2012; 2,40

Rothschild CB, Akots G, Fajans SS, Bowden DW (1992): A microsatellite polymorphism associated with the PLC1 (phospholipase C) locus: identification, mapping, and linkage to the MODY locus on chromosome 20. Genomics $\underline{13}$, 560-564. 
Saiki RK, Scharf S, Faloona F, Mullis KB, Horn GT, Erlich HA, Arnheim N (1985): Enzymatic amplification of beta-globin genomic sequences and restriction site analysis for diagnosis of sickle cell anemia. Science $230,1350-1354$.

Sallmyr A, Fan J, Virgilia R (2008): Genomic instability in myeloid malignancies: Increased reactive oxygen species (ROS), DNA double strand breaks (DSBs) and error-prone repair. Cancer Lett $\underline{270}, 1-9$

Samowitz WS, Slattery ML, Potter JD, Leppert MF (1999): BAT-26 and BAT-40 instability in colorectal adenomas and carcinomas and germline polymorphisms. Am J Pathol $\underline{154}, 1637-$ 1641

Senda T, Shimomura A, lizuka-Kogo A (2005): Adenomatous polyposis coli (Apc) tumor suppressor gene as a multifunctional gene. Anat Sci Int $\underline{80}, 121-131$

Serrano E, Carnicer MJ, Orantes V, Estivill C, Lasa A, Brunet S, Aventin AM, Sierra J, Nomdedeu JF (2008): Uniparental disomy may be associated with microsatellite instability in acute myeloid leukemia (AML) with normal karyotype. Leuk Lymphoma $\underline{49}, 1178-1183$

Sheikhha MH, Tobal K, Liu Yin JA (2002): High level of microsatellite instability but not hypermethylation of mismatch repair genes in therapy-related and secondary acute myeloid leukaemia and myelodysplastic syndrome. Br J Haematol 117, 359-365

Spirio L, Joslyn G, Nelson L, Leppert M, White R (1991): A CA repeat 30-70 KB downstream from the adenomatous polyposis coli (APC) gene. Nucleic Acids Res $\underline{19}, 6348$

Stegmaier K, Pendse S, Barker GF, Bray-Ward P, Ward DC, Montgomery KT, Krauter KS, Reynolds C, Sklar J, Donnelly M, Bohlander SK, Rowley JD, Sallan SE, Gilliland DG, Golub TR (1995): Frequent loss of heterozygosity at the TEL gene locus in acute lymphoblastic leukemia of childhood. Blood 1995 86, 38-44

Stoddart A, Fernald AA, Wang J, Davis EM, Karrison T, Anastasi J, Le Beau MM (2014): Haploinsufficiency of del(5q) genes, Egr1 and Apc, cooperate with Tp53 loss to induce acute myeloid leukemia in mice. Blood $\underline{123}, 1069-1078$ 
Stollmann B, Fonatsch C, Havers W (1985): Persistent Epstein-Barr virus infection associated with monosomy 7 or chromosome 3 abnormality in childhood myeloproliferative disorders. Br J Haematol $\underline{60}, 183-196$

Tasaka T, Lee S, Spira S, Takeuchi S, Nagai M, Takahara J, Koeffler HP (1997): Microsatellite instability during the progression of acute myelocytic leukaemia. $\mathrm{Br} \mathrm{J}$ Haematol $\underline{98}, 219-221$

Tee Y-T, Chen G-D, Lin L-Y, Ko J-L, Wang P-H (2006): Nm23-H1: A metastasis-associated Gene. Taiwan J Obstet Gynecol 노, 107-113

Tischfield JA (1997): Loss of heterozygosity or: How I learned to stop worrying and love mitotic recombination. Am J Hum Genet $\underline{61}$, 995-999

Trapman J, Sleddens HFBM, van der Weiden MM, Dinjens WNM, Konig JJ, Schroder FH, Faber PW, Bosman FT (1994): Loss of heterozygosity of chromosome 8 microsatellite loci implicates a candidate tumor suppressor gene between the loci D8S87 and D8S133 in human prostata cancer. Cancer Res $\underline{54}, 6061-6064$

Vardiman JW, Thiele J, Arber DA, Brunning RD, Borowitz MJ, Porwit A, Harris NL, Le Beau MM, Hellström-Lindberg E, Tefferi A, Bloomfield CD (2009): The 2008 revision of the World Health Organization (WHO) classification of myeloid neoplasms and acute leukemia: rationale and important changes. Blood $\underline{114}, 937-51$

Vogelstein B, Kinzler KW (2004): Cancer genes and the pathways they control. Nat Med 10: 789-799

Weber JL, May PE (1990): Dinucleotide repeat polymorphism at the D4S171 locus. Nucleic Acids Res $\underline{18}, 2202$

Weber JL, Kwitek AE, May PE, Patterson D and Drabkin H (1990): Dinucleotide repeat polymorphisms at the D8S85, D8S87 and D8S88 loci. Nucleic Acids Res $\underline{18}, 4038$

Weinberg RA (1991): Tumor Suppressor Genes. Science 254, 1138-1146

Weissenbach J, Gyapay G, Dib C, Vignal A, Morissette J, Millasseau P, Vaysseix G, Lathrop $M$ (1992): A second-generation linkage map of the human genome. Nature $\underline{359}, 794-801$ 
Will B, Steidl U (2014): Combinatorial haplo-deficient tumor suppression in 7q-deficient myelodysplastic syndrome and acute myeloid leukemia. Cancer Cell 25, 555-557

Yandell DW, Dryja TP (1989): Detection of DNA sequence polymorphisms by enzymatic amplification and direct genomic sequencing. Am J Hum Genet $\underline{45}$, 547-555

Zenklusen JC, Bieche I, Lidereau R, Conti CJ (1994): (C-A) microsatellite repeat D7S522 is the most commonly deleted region in human primary breast cancer. Proc Natl Acad Sci USA $\underline{91}, 12155-12158$

Zhu YM, Das-Gupta EP, Russell NH (1999): Microsatellite instability and p53 mutations are associated with abnormal expression of the $\mathrm{MSH} 2$ gene in adult acute leukemia. Blood $\underline{94}$, $733-740$ 


\section{Anhang}

\section{Abkürzungsverzeichnis}

A

ALL

AML

APS

AraC

BCR-ABL

BSA

BUC

C

CBL

CEBPA

C-FMS

CLL

CML

CMML

CSA

$\mathrm{DAB}$

DMSO

DNA

dNTP

DTT

ECL

EDTA

Egr1

EGTA

FAB

FCS

FLT3

G

GDP

GM-CSF

G-NETT

GTBP
Adenin

Akute lymphatische Leukämie

Akute myeloische Leukämie

Ammoniumperoxidisulfat

Cytarabin

breakpoint cluster region - Abelson murine leukemia viral

oncogene homolog

Bovines Serumalbumin

Bukkalepithel

Cytidin

Casitas B-lineage lymphoma (Proto-Onkogen)

CCAAT/enhancer-binding protein alpha

Colony stimulating factor 1 receptor

Chronisch lymphatische Leukämie

Chronisch myeloische Leukämie

Chronisch myelomonozytäre Leukämie

Catalyzed Signal Amplification System

3,3'-Diaminobenzidin

Dimethylsulfoxide

Deoxyribonucleic acid

Dinukleotidtriphosphat

Dithiothreitol

Enhanced chemoluminescence

Ethylendiamin tetraacetic acid

Early growth response protein 1

Ethylenguanin tetraacetic acid

French American British Collaborative Group

Fetales Kälberserum

FMS-like tyrosine kinase 3

Guanin

Guanosindiphosphat

Granulocyte-macrophage colony-stimulating factor

Gelatine in NETT

G/T binding protein 


\begin{tabular}{|c|c|}
\hline GTP & Guanosintriphosphat \\
\hline hMLH1 & Human MutL homologue 1 \\
\hline hMLHa & Human MutL homologue $\alpha$ \\
\hline HNPCC & Hereditary non-polyposis colorectal cancer \\
\hline hPMS1, -2 & Human postmeiotic segregation increased 1, -2 \\
\hline hMSH2, $-3,-6$ & Human MutS homologue 2, -3, -6 \\
\hline IDL & Insertion/deletion loop \\
\hline IL & Interleukin \\
\hline IRF1 & Interferon regulatory factor 1 \\
\hline ISCN & International system for human cytogenetic nomenclature \\
\hline ITD & Internal tandem duplications \\
\hline KIT & Tyrosinkinase \\
\hline KM & Knochenmark \\
\hline LDH & Laktatdehydrogenase \\
\hline $\mathrm{LOH}$ & Loss of heterozygosity \\
\hline M-CSF & Macrophage colony-stimulating factor \\
\hline MDS & Myelodysplastisches Syndrom \\
\hline MGMT & $\mathrm{O}^{6}$-Methylguanin-DNA-Methyltransferase \\
\hline MLL3 & mixed lineage leukemia 3 \\
\hline MMR & DNA-Mismatch-Repair-System \\
\hline NPM1 & Nucleophosmin 1 \\
\hline MRP1 & Multiple drug resistance protein 1 \\
\hline MSI & Mikrosatelliteninstabilität \\
\hline mTOR & mechanistic Target of Rapamycin \\
\hline NER & Nucleotide-excision-repair \\
\hline NETT & NaCL, EDTA, Tris, Triton X-100 \\
\hline NEZ & nicht erythroide Zellen \\
\hline NP-40 & Nonidet P-40 \\
\hline OFD & Octamer-frequency-disparity-Methode \\
\hline PAGE & Polyacrylamidgel-Elektrophorese \\
\hline PBS & Phosphate buffered saline \\
\hline PCR & Polymerase chain reaction (Polymerasekettenreaktion) \\
\hline PML & Promyelocytic leukemia protein \\
\hline PMSF & Phenylmethylsulfonylfluorid \\
\hline PTD & partial tandem duplication \\
\hline RARA & Retinoic acid aeceptor alpha \\
\hline $\mathrm{RER}^{+}$ & Replication error positive \\
\hline
\end{tabular}




$\begin{array}{ll}\text { RIPA } & \text { Radio-immuno-precipitation-assay } \\ \text { RNA } & \text { Ribonucleic acid } \\ \text { RAS } & \text { Rat sarcoma (Proto-Onkogen) } \\ \text { ROS } & \text { Reactive oxygen species } \\ \text { RUNX } & \text { Runt-related transcription factor } \\ \text { SDS } & \text { Sodium dodecylsulfate (Natriumdodecylsulfat) } \\ \text { T } & \text { Thymin } \\ \text { TBS } & \text { Tris, Borsäure, NaCl } \\ \text { TCA } & \text { Trichloracetic acid (Trichloressigsäure) } \\ \text { TEMED } & \text { N,N,N',N'-Tetramethylethylendiamin } \\ \text { t-MDS } & \text { Therapieinduziertes MDS } \\ \text { t-RAEB } & \text { Therapieinduzierte RAEB } \\ \text { Tris } & \text { Tris(hydroxymethyl)aminomethan } \\ \text { Upm } & \text { Umdrehungen pro Minute } \\ \text { WHO } & \text { World Health Organization } \\ \text { WS } & \text { Werner-Syndrom }\end{array}$




\section{Abbildungsverzeichnis}

Abb. 1: $\quad \mathrm{LOH}$ an sieben verschiedenen Loci

Abb. 2: Immunhistochemische Untersuchung unter Verwendung eines Primärantikörpers gegen hMSH2

Abb. 3: hMSH2-Expressionsanalyse mittels Western Blot-Analyse von Zelllysaten aus AML-Blasten von zwölf verschiedenen Patienten

\section{Tabellenverzeichnis}

Tab. 1: Einteilung der AML entsprechend der FAB-Klassifikation Seite 6

Tab. 2: $\quad$ Einteilung der AML in Prognosegruppen nach Zytogenetik und molekularen Mutationen

Seite 7

Tab. 3: Loci und Primer

Tab. 4: Karyotypen der untersuchten Patienten und Ergebnisse der Mikrosatellitenanalyse

Tab. 5: Immunhistochemische Untersuchung unter Verwendung eines Primärantikörpers gegen hMSH2

Tab. 6: Karyotyp, hMSH2-Expression in Immunhistochemie und Western Blot sowie LOH-Nachweis 


\section{Danksagung}

Mein besonderer Dank gilt Frau Prof. Dr. med. F. Alves für die Überlassung des Themas und die jederzeit konstruktive und engagierte Betreuung.

Ebenso danken möchte ich Herrn Prof. Dr. med. D. Haase für die wertvollen Tipps und Anregungen.

Mein Dank gilt auch Herrn Dr. med. Lienhard Maeck, der mich in die Methoden eingearbeitet hat und mich mit seinem Rat unterstützte.

Außerdem danke ich Herrn Marco Ledwon für die Durchführung des Western Blots.

Ferner danke ich meinen Mitdoktoranden und den MTAs im Labor für die gute Zusammenarbeit sowie allen, die mir bei der Beschaffung der Patientenproben geholfen haben, insbesondere Frau U. Schmidt-Martens, Frau U. Bußmann und Herrn R. Steffens. 